\title{
Cooperation in Research and Development
}

\author{
Réka Horváth
}

July 2001

Departament d'Economia i d'Història Econòmica

Universitat Autònoma de Barcelona

International Doctorate in Economic Analysis

Supervisor: David Pérez-Castrillo 
I am very grateful to David Pérez-Castrillo for his support and advise and for his patience with my taste for empirical research.

I would also like to thank John Van Reenen for forcing me to learn some proper econometrics and giving me many useful and practical comments. I am also grateful to Bruno Cassiman, Inés Macho-Stadler, Joel Sandonís and Reinhilde Veugelers for their continuing willingness to listen to my ideas and for their many helpful comments. I also appreciate the comments of Giacinta Cestone and Xavier Martinez-Giralt.

I would also like to thank all my friends in the IDEA program who inspired me to work harder on my research.

I am also grateful to Wendy Carlin for showing me how fun economics can be and to Christian Koboldt and Dan Maldoom for their patience.

I appreciate the help of Mercè Vicente with the submission of the thesis.

I would like to thank my family and my friends in Hungary for their continuous support, especially my mother, my sister Fruzsi, my nephews Máté and Bálint and my niece Lili.

And last but not least I am very grateful to João for being there for me.

This research was undertaken with support from the European Union's Phare ACE Programme. I also acknowledge the financial support of DGES PB 97-0181. 


\section{Contents}

1 Introduction 1

2 Information sharing and limited liability in cooperative research $\quad 6$

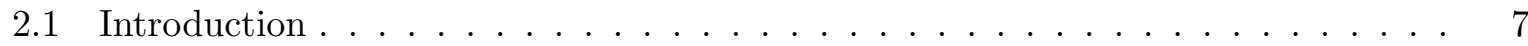

2.2 The benchmark model $\ldots \ldots \ldots \ldots \ldots \ldots$

2.2 .1 Equilibrium disclosure . . . . . . . . . . . . . . . . . 13

2.2 .2 Equilibrium debt level . . . . . . . . . . . . . . . . . . 16

2.3 Decision on setting up the research joint venture f . . . . . . . . . . 18

2.3.1 Firms decide on debt levels individually . . . . . . . . . . . . . . . . . 19

2.3.2 Firms decide on debt levels together . . . . . . . . . . . . . . . . 21

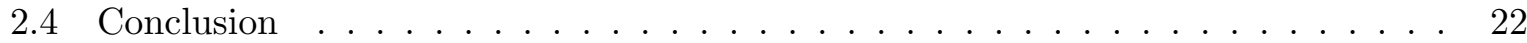

3 Cooperative research and firm performance $\quad 23$

3.1 Introduction . . . . . . . . . . . . . . . . . . . . . 24

3.2 Empirical investigation . . . . . . . . . . . . . . . . 28

3.2 .1 The model . . . . . . . . . . . . . . . . . . . . . 28

3.2 .2 Estimation . . . . . . . . . . . . . . . . . . . . . 29

3.2 .3 Data . . . . . . . . . . . . . . . . . . . . 30

3.3 Results . . . . . . . . . . . . . . . . . . . . . . 31

3.3.1 Total RJV effect . . . . . . . . . . . . . . . . . . . 32

3.3 .2 Direct RJV effect . . . . . . . . . . . . . . . . . . . . 35

3.3.3 Vertical and horizontal research joint ventures . . . . . . . . . . . . 37

3.3.4 Different lags of the RJV participation . . . . . . . . . . . . . . 37

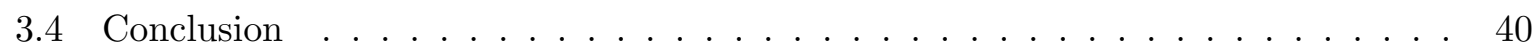


4.1 Introduction . . . . . . . . . . . . . . . . . . . . . . . . . 42

4.2 Empirical investigation . . . . . . . . . . . . . . . . 44

4.2 .1 Incentives to form research joint ventures . . . . . . . . . . . . . . . 44

4.2.2 Cost sharing in horizontal research joint ventures . . . . . . . . . . . 45

4.2.3 Limited liability and incentives to form horizontal research joint ventures 48

4.2.4 European legislation and horizontal research joint ventures . . . . . . . . 48

4.3 Results . . . . . . . . . . . . . . . . . . . . . . . 52

4.3.1 Incentives to form research joint ventures . . . . . . . . . . . . 52

4.3.2 Cost sharing in horizontal research joint ventures . . . . . . . . . . . . . 54

4.3.3 Limited liability and incentives to form horizontal research joint ventures $\quad 59$

4.3.4 European legislation and horizontal research joint ventures . . . . . . . . 61

4.4 Conclusion . . . . . . . . . . . . . . . . . . . . . . . 62

$\begin{array}{ll}\text { Appendix A: Proofs } & 63\end{array}$

$\begin{array}{ll}\text { Appendix B: Descriptive statistics } & 65\end{array}$

$\begin{array}{ll}\text { Bibliography } & 71\end{array}$ 
Chapter 1

\section{Introduction}


Cooperation in research and development is part of the new strategies developed by firms in an increasingly global and competitive economic environment. The advantages of R\&D cooperation for the participating firms are well known. Firms involved in R\&D cooperation can capture economies of scale. They can also take advantage of the complementarities of their knowhow and can avoid costly duplications of their results. Another advantage of R\&D cooperation is internalizing spillovers, as even patents do not give full protection against imitations.

The importance of research alliances is acknowledged by government policy in various countries. Research joint ventures (RJVs) are granted exemption from anti-trust laws and their formation is encouraged by subsidies. In Japan, industrial policy actively supported the formation of research consortia since 1959. The spectacular Japanese growth in the 60's and 70's was partly attributed to cooperative research. Therefore, at the beginning of the 80's the US and European legislation made efforts to promote R\&D cooperation.

In the USA, the National Cooperative Research Act (1984) and the National Cooperative Research and Production Act (1993) guarantee that every research alliance filed at the Federal Register is evaluated separately if they fail to fulfill antitrust laws. In the 90's, the Clinton administration significantly increased the budget of the Advanced Technology Program that funds collaborative research projects in the private sector to encourage joint research.

In Europe, Article 81(3) (former 85(3)) of the EC treaty allows the EC Commission to exempt research alliances from Article 81(1) (which prohibits restrictive practices between firms which may affect the trade between the member states or the competition within the EC). In 1985, the Commission granted a block exemption to certain categories of R\&D agreements. Moreover, in some cases it allows the joint exploitation and marketing of the results of that R\&D. Furthermore, there are also several programs established and funded by the European Commission to promote cooperation in research. The European Strategic Program for Research in Information Technologies (ESPRIT) is by far the largest of these programs. Between 1983 and 1996 around 9000 organizations participated in over 1200 ESPRIT-financed projects.

Table 1.1: New research joint ventures participants worldwide (1986-1995)

\begin{tabular}{ccccccccccc}
\hline \hline & 1986 & 1987 & 1988 & 1989 & 1990 & 1991 & 1992 & 1993 & 1994 & 1995 \\
\hline number of firms & 22 & 15 & 23 & 47 & 217 & 392 & 513 & 499 & 675 & 804 \\
\hline
\end{tabular}

Source: SDCA-SDC Worldwide Joint Ventures \&3 Alliances.

Table 1.1 illustrates the growing number of firms participating in research joint ventures (RJVs) with an initial stake of at least 1 million USD. Within nine years, the number of firms 
that participate in newly formed RJVs grew by a factor of almost 40 .

Following this upsurge of interest, economists also turned their attention towards research joint ventures. By now, there is a large body of theoretical literature dealing with several aspects of cooperative research. A substantial part of this work analyzes firms' incentives to engage in cooperative research and the characteristics of firms that participate in research consortia. Most of the attention was paid to internalizing spillovers as a key incentive of RJV formation. Similarly, the main focus of the empirical literature is also the analysis of these incentives.

The work presented in this dissertation contributes both to the theoretical and the empirical literature on research joint ventures.

In Chapter 2, I analyze the problem that in spite of the advantages mentioned above, research joint ventures do not always guarantee fruitful cooperation as partners may not deliver what is expected from them. Also, there are cases when firms do not start potentially very profitable RJVs. These failures can be due to the existence of asymmetric information between the partners. On the one hand, partners may not be well informed about the research abilities of the other firms. On the other hand, even if the research partners know each others' abilities, they cannot contract the transfer of the know-how and without the required amount of information disclosure the RJV is not profitable. This second problem arises especially when firms are competitors either in the product market or in other R\&D activities, or there is another cost associated with the information transfer. In these cases firms do not have the right incentives to share their knowledge.

I propose a novel way to alleviate the problem of information sharing when partners in a research joint venture are competitors in the product market. I show that firms can use their debt level as a commitment to disclose know-how. I present a model where debt is a main strategic instrument used by a firm participating in (or looking for partners to form) a RJV. I find that there is a direct relationship between the debt of a firm and the incentives to disclose its know-how in a RJV. Therefore, the partners observing the debt level of a firm can foresee its disclosure. Moreover, I show conditions on the profit functions under which firms, in equilibrium, finance at least partially with debt. Due to the possibility of debt financing, the equilibrium level of disclosure is higher than in case of equity/internal financing. That is, the leverage acts as a commitment device to share knowledge.

Furthermore, whenever firms have the possibility to write down contracts on their debt levels, they can successfully cooperate in order to maximize their joint value. I show that in this case firms decide to finance completely by debt and the level of information disclosure is higher than without the contract. Hence, contracting on debt levels is sometimes a partial substitute of 
contracting on disclosure of know-how.

Therefore, the possibility of debt financing can improve welfare in two ways. First, if firms are already in the RJV, their disclosure can be higher by using debt. Second, in some cases there are joint ventures that would not start without the debt as a commitment.

In the next two chapters I use econometric techniques to further investigate different aspects of cooperative research.

In Chapter 3, I provide a microeconometric analysis of the impact of RJV participation on productivity. As discussed above, productivity growth, as the engine of economic growth, is one of the main concerns of industrial policy. Research joint ventures are exempt from antitrust laws because they are considered to promote efficiency. This can be either productive efficiency or other types, like R\&D cost sharing. Also, as we saw before, one of the reasons why firms form RJVs is to gain efficiency. This is why analyzing the effects of research joint venture participation on productivity is an interesting issue.

Evaluating the overall benefits of cooperative research is very difficult because the cooperation may have an impact both on R\&D spending and the competitive structure of the industry. Firms that are cooperating in research and development might be inclined to do so even in the product market competition, a behaviour that should concern antitrust authorities.

I study the productivity implications of research joint venture participation using a large panel of European, Japanese and US companies. Furthermore, using a sample of around 1500 US firm with available information on $R \& D$ spending I separate the effect of $R \& D$ investment and RJV participation on productivity. I find evidence that joint R\&D increases productivity. The result is similar even when the effect through $R \& D$ investment is separated. The results suggest that when $R \& D$ spending is controlled for, it is the horizontal form of $R \& D$ cooperation that brings about the most significant productivity improvement. This is consistent with the findings of the theoretical literature that cost-sharing is an important incentive in forming horizontal research consortia.

In Chapter 4, I analyze the firms' incentives to engage in cooperative research. As seen above, the estimations are conducted on unusually large samples that enable us to obtain robust results. After conducting a simple investigation into general firm characteristics that are associated with RJV participation, the analysis mainly focuses on horizontal research joint ventures, i.e. when firms engage in cooperative research with their direct competitors. The main objective of the paper is to find evidence for cost sharing in horizontal research joint ventures, as the theoretical literature argues that cost sharing is important mostly in this type of alliances. I find evidence of cost sharing. 
In the same chapter, I also investigate the effect of debt levels on horizontal RJV participation. As discussed above, in Chapter 2 I find that firms with a more leveraged capital structure are less reluctant to disclose their know-how to competitors and therefore competitors are more willing to engage in cooperative $\mathrm{R} \& \mathrm{D}$ with them. The empirical analysis finds evidence for the existence of this effect.

In the course of this work, I have focused on the incentives to form RJVs and the impact of conducting cooperative research on firm performance. I have found both theoretical and empirical evidence that firms can use their debt level as a commitment to deliver what is expected from them in a horizontal research joint venture. Furthermore, I have also found an empirical link between $\mathrm{R} \& \mathrm{D}$ cooperation and gains in total factor productivity. 
Chapter 2

Information sharing and limited

liability in cooperative research 


\subsection{Introduction}

The advantages of R\&D cooperation for the participating firms are well known. Firms involved in $R \& D$ cooperation can capture the economies of scale. They can also take advantage of the complementarities of their know-how and can avoid costly duplications of their results. Another advantage of R\&D cooperation is internalizing spillovers. Choi (1993) argues that research cooperations are formed as a response to a free riding problem: even patents do not give full protection against imitations. ${ }^{1}$

In spite of the advantages mentioned above, research joint ventures (RJV) do not always guarantee fruitful cooperation as partners may not deliver what is expected from them. Also, there are cases when firms do not start potentially very profitable RJVs. These failures can be due to the existence of asymmetric information between the partners. On the one hand, partners may not be well informed about the research abilities of the other firms. On the other hand, even if the research partners know each others' abilities, they cannot contract the transfer of the know-how, and without the required amount of information disclosure the RJV is not profitable. This second problem arises especially when firms are competitors either in the product market or in other R\&D activities, or there is another cost associated with the information transfer. In these cases firms do not have the right incentives to share their knowledge.

The reasons of the failure of RJVs and the analysis of this moral hazard problem are discussed by Gandal and Scotchmer (1993), Sandonís (1993), Veugelers and Kesteloot (1994), Kesteloot and Veugelers (1995) and Pérez-Castrillo and Sandonís (1996). The latter analyze the moral hazard problem of disclosing know-how when the research partners are competitors in the product market. The authors construct a model where the transfer of the knowledge of a firm decreases the cost of the joint research activity. At the same time, it also decreases the product market profit of the disclosing firm as the other firm can use the information to improve its situation in the output market. So, participating firms may have incentives to let the RJV break down rather than share their know-how. The authors show that in some cases this situation can be resolved by contracts.

Other solutions to overcome this moral hazard problem are offered by Choi (1992) and Bhattacharya et al. (1992). Choi (1992) argues that if there is another research input which is contractible, first best can be approached when the two inputs become more complementary. Bhattacharya et al. (1992) find that licensing can be an instrument to implement the optimal information sharing and efficient R\&D effort levels, provided that firms receiving know-how can

\footnotetext{
${ }^{1}$ Other articles on the social and private incentives to carry out cooperative research are for example by Martin (1994), De Bondt and Veugelers (1991) and De Bondt et al. (1992).
} 
be charged with an entrance fee. Unfortunately, this condition is hard to fulfill.

In this paper, I propose another way to alleviate the problem of information sharing when partners in a research joint venture are competitors in the product market. I show that (under some conditions) firms can use their debt level as a commitment to disclose know-how.

According to Kamien and Schwartz (1982), innovative activities are mostly financed internally. They argue that it is due to two reasons: first, banks can not monitor the innovation process, thus creating scope for free riding. Second, in order to get loans, firms would have to disclose information about their research, risking that the disclosed information may benefit others. However, Jensen and Showalter (1999) claim that pure internal financing of R\&D is not that common. They describe the case of Austin, Texas where many high-tech startup companies were able to secure credit lines. Also, the external financing through venture capital deals is gaining increasing importance.

I present a model that develops the idea that the leverage is a main strategic instrument by a firm participating in (or looking for partners to form) a RJV. I find that there is a direct relationship between the leverage of a firm and its incentives to disclose its know-how in a RJV. Therefore, the partners observing the debt level of a firm can foresee its disclosure. Moreover, I show conditions on the profit functions under which firms, in equilibrium, finance at least partially with debt. Due to the possibility of debt financing, the equilibrium level of disclosure is higher than in case of equity/internal financing. That is, the leverage acts as a commitment device to share knowledge.

Furthermore, whenever firms have the possibility to write down contracts on their debt levels, they can successfully cooperate in order to maximize their joint value. I show that in this case firms decide to finance completely by debt and the level of information disclosure is higher than without the contract (although still lower than the first best). Hence, contracting on debt levels is sometimes a partial substitute of contracting on disclosure of know-how.

The possibility of bankruptcy is the key explanation of the previous results. Different debt levels provide different incentives for shareholders to disclose know-how since they only care about the size of the profit when it is positive (otherwise they do not get anything). For each leverage, there is a different threshold for which income becomes positive. Therefore, shareholders choose a different optimal disclosure for each leverage.

The influence of a leveraged financial structure on a firm's behaviour is well known. Brander and Lewis (1986) analyze the behavior of firms competing à la Cournot. They show that under certain conditions, a higher debt level implies more aggressive behavior in the product market. Showalter (1995) modifies the Brander and Lewis model for Bertrand competition and finds that 
the use of strategic debt is advantageous only if demand conditions are uncertain. If costs are uncertain, debt has a strategic disadvantage. He also presents empirical evidence supporting his theory (Showalter, 1999). Bhattacharya and Chiesa (1995) analyze information sharing and borrowing in a different setting than my paper. They find that with bilateral bank-borrower ties know-how is not disclosed, while under multilateral financing there might be knowledge sharing between output market competitors. Other studies that analyze the relationship between financial structure and output market performance are Ross (1977), Myers and Majluf (1984), Narayanan (1988), and Poitevin (1989).

The structure of the paper is the following: section 2 introduces the benchmark model when the firms already have decided on participating in joint research. I show how different debt levels induce different information disclosure, and what is the optimal decision on debt levels. In section 3, I incorporate the firms' decision on setting up the RJV. I show that with the possibility of debt financing RJV's start more often than without this possibility. Section 4 concludes the analysis and discusses the possible policy implications. All proofs are in Appendix A.

\subsection{The benchmark model}

Consider a research joint venture that consists of two risk neutral firms that look to develop a new product or process. Besides working together in the research activity, the firms are competitors in the product market. ${ }^{2}$ That is, the expected profit of a firm is the sum of its (expected) operating profit in the RJV and the product market profit.

There is no asymmetric information in the sense that firms know each others' know-how level and profit functions, but the disclosure of information cannot be contracted. The disclosed information increases the profit of the joint research activity. It may decrease for example the cost of research through the smaller number of experiments needed to find the right research path. At the same time, the disclosing firm reveals useful information for the product market, so for the rival. Thus, product market profit of the rival increases while its own profit decreases.

The timing of the interaction between the firms is the following. First, the firms choose the financial structure (amount of debt). Second, each of the firms decides about the level of information disclosure, that is the input of the joint research activity. Then they learn about their profits (which stems from both the research and the output market), and finally they pay

\footnotetext{
${ }^{2}$ The relationship between the firms could be also vertical, the important thing is that there is a cost associated with information disclosure. I refer to competitors because the intuition is more clear in this case.
} 
their debt obligations (if they can). Notice that we are assuming that the decision of forming the RJV has already been taken (see Section 3 for the optimal decision of the firms). Figure 2.1 shows the timing of the game.

\begin{tabular}{lll}
\hline & & profit is \\
financial & information & realized \\
decisions & disclosure & (possible bankruptcy)
\end{tabular}

Figure 2.1: Timing of the benchmark model

The operating profit of firm $i$ in the RJV is its share $\left(\alpha^{i}\right)^{3}$ of the total operating profit of the RJV $(P)$. I assume that the parameter $\alpha^{i}$ is already set: firms have included it in the RJV contract. The total operating profit of the RJV is a function of the knowledge disclosed by the research partners $\left(\gamma^{1}, \gamma^{2}\right)$. I assume that the more know-how firms disclose the higher is the operating profit of the RJV. The profits also depend on an exogenous random variable $(v)$ with well behaving density function $f(v)$ on the support $[\underline{v}, \bar{v}]$. I normalize $v$ so that profit increases with it. Therefore, the total operating profits are represented by a function $P\left(v, \gamma^{1}, \gamma^{2}\right)$, with:

$$
\begin{aligned}
& P_{\gamma^{i}}>0, \quad i=1,2 ; \\
& P_{v}>0 .
\end{aligned}
$$

The operating profit of the RJV is the difference between the patent value and the variable cost. For example, one could view $v$ as a shock that affects the patent value: in good states of nature the patent value is high, in bad states it is low. Similarly, $v$ could affect the variable cost of the RJV. Some possible simple forms of the profit $P$ are: $P\left(v, \gamma^{1}, \gamma^{2}\right)=v-v c\left(\gamma^{1}, \gamma^{2}\right)$, $P\left(v, \gamma^{1}, \gamma^{2}\right)=v-c\left(\gamma^{1}, \gamma^{2}\right)$, or $P\left(v, \gamma^{1}, \gamma^{2}\right)=v-(\bar{v}-v) c\left(\gamma^{1}, \gamma^{2}\right)$. Note that although all three functional forms satisfy (2.1) and (2.2), they differ in the behaviour of marginal profit in good and bad states.

Firms compete in the product market. As discussed above, the product market profit of firm $i\left(B^{i}\right)$ also depends on the quantity of disclosed knowledge. As disclosing know-how helps the competitor, own disclosure decreases the product market profit. At the same time, the disclosure of the other firm increases the product market profit. For convenience, I assume that

\footnotetext{
${ }^{3}$ Throughout the paper superscript letters denote indices while subscript letters stand for partial derivatives.
} 
there is no uncertainty about the product market profits. The product market profit function of firm $i$ is represented by a function $B^{i}\left(\gamma^{1}, \gamma^{2}\right)$, with ${ }^{4}$

$$
\begin{gathered}
B_{\gamma^{i}}^{i}<0, \\
B_{\gamma^{j}}^{i}>0 .
\end{gathered}
$$

I assume that the output market profit and the profit from the research joint venture can be perfectly separated. This assumption does not influence the results obtained in the paper. Therefore, the expected profit (П) of firm $i$ is:

$$
\Pi^{i}=\int_{\underline{v}}^{\bar{v}}\left[\alpha^{i} P\left(v, \gamma^{1}, \gamma^{2}\right)+B^{i}\left(\gamma^{1}, \gamma^{2}\right)\right] f(v) d v
$$

As a further simplification, I assume that the sum of the product market profits and the profit shares of the firms from the RJV is always nonnegative. That is, $\alpha^{i} P\left(v, \gamma^{1}, \gamma^{2}\right)+B^{i}\left(\gamma^{1}, \gamma^{2}\right) \geq 0$ for all $\left(\gamma^{1}, \gamma^{2}\right)$.

Before starting the research consortium, each firm has to pay a fixed cost. Firms can raise money to pay this cost by issuing new shares or bonds. I denote by $D^{i}$ the amount of money firm $i$ has to pay back to the bank in case of borrowing. Note that $D^{i}$ is the amount the firm has to pay back, and not the amount the bank lends to them. For simplicity, I will consider only "strategic debt", that is debt levels which can lead to bankruptcy $\left(\alpha^{i} P\left(\underline{v}, \gamma^{1}, \gamma^{2}\right)+B^{i}\left(\gamma^{1}, \gamma^{2}\right) \leq D^{i}\right)$. If the debt does not reach this critical level I call it "zero debt level". On the other hand, I assume that there are realizations for which the firm can repay its debt $\left(\alpha^{i} P\left(\bar{v}, \gamma^{1}, \gamma^{2}\right)+B^{i}\left(\gamma^{1}, \gamma^{2}\right) \geq D^{i}\right)$.

I denote $\tilde{v}^{i}$, with $\underline{v} \leq \tilde{v}^{i} \leq \bar{v}$, the threshold level of $v$ for which the firm's profit is equal to its debt obligation, that is:

$$
\alpha^{i} P\left(\tilde{v}^{i}, \gamma^{1}, \gamma^{2}\right)+B^{i}\left(\gamma^{1}, \gamma^{2}\right)-D^{i}=0
$$

The probability of bankruptcy is then $F\left(\tilde{v}^{i}\right)$ where $F(v)$ is the distribution function of $v$. It is clear that $\tilde{v}^{i}$, thus the probability of bankruptcy, is increasing in $D^{i}$ since higher debt implies higher risk of not paying it back. Also, $\tilde{v}^{i}$ is a decreasing function of the disclosed know-how of the other firm $\left(\gamma^{j}\right)$, since the other firm's information transfer increases the firm's total profit. Formally:

\footnotetext{
${ }^{4}$ For notational convenience, I will always refer to $j$ as the firm different from $i$.
} 


$$
\begin{gathered}
\frac{d \tilde{v}^{i}}{d D^{i}}=-\frac{-1}{\alpha^{i} P_{\tilde{v}^{i}}}>0, \\
\frac{d \tilde{v}^{i}}{d \gamma^{j}}=-\frac{\alpha^{i} P_{\gamma^{j}}+B_{\gamma^{j}}^{i}}{\alpha^{i} P_{\tilde{v}^{i}}}<0 .
\end{gathered}
$$

However, it is not possible to establish a similar property for $\tilde{v}^{i}$ as a function of the own disclosure. On one hand, own disclosure increases the RJV profit, thus decreases the probability of bankruptcy. On the other hand, it decreases the output market profit, thus $F\left(\tilde{v}^{i}\right)$ increases:

$$
\frac{d \tilde{v}^{i}}{d \gamma^{i}}=-\frac{\alpha^{i} P_{\gamma^{i}}+B_{\gamma^{i}}^{i}}{\alpha^{i} P_{\tilde{v}^{i}}} .
$$

In those states of nature where the total profit of a firm is lower than its debt, the shareholders don't get anything, all the profit goes to the debtholders. Thus, the value of firm $i$ for its shareholders is:

$$
S V^{i}=\int_{\tilde{v}^{i}}^{\bar{v}}\left[\alpha^{i} P\left(v, \gamma^{1}, \gamma^{2}\right)+B^{i}\left(\gamma^{1}, \gamma^{2}\right)-D^{i}\right] f(v) d v
$$

Let us note that in this model going bankrupt means that the sum of R\&D and product market profit is lower than the debt obligation. That is, not only the RJV goes bankrupt in bad states. This is certainly true when cooperative research is carried out without setting up a separate firm for the joint project. On the other hand, even in the form of a separate entity many RJVs operate during long periods with losses. The real constraint is the parent firms overall performance.

Consider now the firm's value for the debtholders. They obtain $D^{i}$ in case $v \geq \tilde{v}^{i}$ and all the profit of the firm if the profit is less than $D^{i}$. Thus the debt value of firm $i$ is:

$$
\begin{aligned}
D V^{i} & =\int_{\tilde{v}^{i}}^{\bar{v}} D^{i} f(v) d v+\int_{\underline{v}}^{\tilde{v}^{i}}\left[\alpha^{i} p\left(v, \gamma^{1}, \gamma^{2}\right)+B^{i}\left(\gamma^{1}, \gamma^{2}\right)\right] f(v) d v= \\
& =\int_{\underline{v}}^{\tilde{v}^{i}}\left[\alpha^{i} p\left(v, \gamma^{1}, \gamma^{2}\right)+B^{i}\left(\gamma^{1}, \gamma^{2}\right)\right] f(v) d v+\left[1-F\left(\tilde{v}^{i}\right)\right] D^{i} .
\end{aligned}
$$

I want to characterize the subgame perfect equilibrium of the model. First, I will describe how the equilibrium disclosure changes with different debt levels. Then, I will characterize the optimal choice of debt. 


\subsubsection{Equilibrium disclosure}

In the second stage of the game the managers of the firms decide on the optimal level of disclosure to maximize the equity values, given the debt the firm has to repay. I make the reasonable assumption that after providing the debt the bank does not have any influence on the decisions of the managers. Thus, the managers represent the shareholders. ${ }^{5}$

The objective of firm $i$ 's shareholders is to maximize $S V^{i}$ :

$$
\operatorname{Max}_{\gamma^{i}} \int_{\tilde{v}^{i}}^{\bar{v}}\left[\alpha^{i} p\left(v, \gamma^{1}, \gamma^{2}\right)+B^{i}\left(\gamma^{1}, \gamma^{2}\right)-D^{i}\right] f(v) d v .
$$

Assuming an interior solution (later I will briefly discuss the relaxation of this assumption), the optimal $\gamma^{i}$ satisfies the following first order condition:

$$
\begin{aligned}
S V_{\gamma^{i}}^{i} & =\int_{\tilde{v}^{i}}^{\bar{v}}\left[\alpha^{i} P_{\gamma^{i}}+B_{\gamma^{i}}^{i}\right] f(v) d v- \\
& -\frac{d \tilde{v}^{i}}{d \gamma^{i}}\left(\alpha^{i} P\left(\tilde{v}^{i}, \gamma^{1}, \gamma^{2}\right)+B^{i}\left(\gamma^{1}, \gamma^{2}\right)-D^{i}\right)=0 .
\end{aligned}
$$

Using (2.6) this condition simplifies:

$$
S V_{\gamma^{i}}^{i}=\int_{\tilde{v}^{i}}^{\bar{v}}\left[\alpha^{i} P_{\gamma^{i}}+B_{\gamma^{i}}^{i}\right] f(v) d v=0
$$

This condition gives us firm i's best reply function: the optimal disclosure as a function of the other firm's information transfer. The optimal level of disclosure is such that the expected marginal cost of the disclosure $\left(-\int_{\tilde{v}^{i}}^{\bar{v}} B_{\gamma^{i}}^{i} f(v) d v\right)$ equals to the expected marginal revenue $\left(\int_{\tilde{v}^{i}}^{\bar{v}}\left[\alpha^{i} P_{\gamma^{i}}\right] f(v) d v\right)$.

I assume the second order condition to hold, and I make the standard assumption for the Nash equilibrium to be stable and unique:

\section{Assumption 2.1}

$$
\begin{aligned}
& S V_{\gamma^{i} \gamma^{i}}^{i}<0 \quad \text { for all }\left(\gamma^{1}, \gamma^{2}\right) \text {, } \\
& S V_{\gamma^{i} \gamma^{i}}^{i} S V_{\gamma^{j} \gamma^{j}}^{j}-S V_{\gamma^{i} \gamma^{j}}^{i} S V_{\gamma^{i} \gamma^{j}}^{j}>0 \quad \text { for all }\left(\gamma^{1}, \gamma^{2}\right) \text {. }
\end{aligned}
$$

${ }^{5}$ I exclude the principal-agent problem between managers and shareholders. 
Note that the second derivative is:

$$
S V_{\gamma^{i} \gamma^{i}}^{i}=\int_{\tilde{v}^{i}}^{\bar{v}}\left[\alpha^{i} P_{\gamma^{i} \gamma^{i}}+B_{\gamma^{i} \gamma^{i}}^{i}\right] f(v) d v+\frac{\left(\alpha^{i} P_{\gamma^{i}}+B_{\gamma^{i}}^{i}\right)^{2}}{\alpha^{i} P_{\tilde{v}^{i}}} .
$$

Since the second term of this expression is positive, the first term necessarily should be negative for the second order condition to hold.

Given the best reply function for a certain level of debt $D^{i}$, one can investigate the effect of a change in $D^{i}$ on the best reply of firm $i$. Using the Implicit Function Theorem:

$$
\frac{d \gamma^{i}}{d D^{i}}=-\frac{-\frac{d \tilde{v}^{i}}{d D^{i}}\left(\alpha^{i} P_{\gamma^{i}}+B_{\gamma^{i}}^{i}\right) f(\tilde{v})}{S V^{i} \gamma^{i} \gamma^{i}} .
$$

The next proposition summarizes this result:

Proposition 2.1 The best reply function of firm $i$ has the following properties:

a) If $P_{\gamma v}>0$, the optimal disclosure of firm i for a given level of disclosure of the other firm increases with the debt $D^{i}$.

b) If $P_{\gamma v}=0$, the optimal disclosure of firm $i$ for a given level of disclosure of the other firm does not depend on the debt $D^{i}$.

c) If $P_{\gamma v}<0$, the optimal disclosure of firm i for a given level of disclosure of the other firm decreases with the debt $D^{i}$.

The proposition says that the best reply function of firm $i$ shifts outward for higher debt if $P_{\gamma v}>0$. The best reply function of firm $i$ shifts inward with the debt level if the patent value and the know-how are strategic substitutes. However, the best reply function does not shift with the debt in the third case. ${ }^{6}$

Note that debt influences information sharing through the threshold of $v(\tilde{v})$. If the marginal gain from sharing more information changes with $v$, then disclosing more know-how influences the profit differently above and below the threshold. The shareholders want to maximize profit above the threshold. Thus, whenever $P_{\gamma v}>0$, the realizations of $v$ that matter are those for which disclosing information is more valuable. That is, when the debt (thus the threshold) increases, it is optimal to disclose more know-how. On the contrary, if $P_{\gamma v}<0$, the shareholders'

\footnotetext{
${ }^{6}$ Now I can sign the derivative in expression (2.9). If the shock and the information are strategic complements, the threshold value of $v$ is increasing in own disclosure. For the opposite case the sign of the derivative is negative.
} 
income is positive in states when one unit of information share is worth less. Therefore, when debt (thus the threshold) increases, disclosing less know-how is optimal. ${ }^{7}$

In order to understand this result, let us take back the previous examples. We saw three different simple functional forms for the RJV's operating profit. If $P\left(v, \gamma^{1}, \gamma^{2}\right)=v-v c\left(\gamma^{1}, \gamma^{2}\right)$, we are in the first case of Proposition 2.1. In good states one unit of disclosed know-how decreases the variable cost more than in bad states, thus the marginal profit is an increasing function of the state of nature $\left(P_{\gamma v}>0\right)$.

If $P\left(v, \gamma^{1}, \gamma^{2}\right)=v-c\left(\gamma^{1}, \gamma^{2}\right)$ we are in case $b$ of the previous proposition. The change in the variable cost (thus the marginal profit) is the same in all states of the nature $\left(P_{\gamma v}=0\right)$.

If $P\left(v, \gamma^{1}, \gamma^{2}\right)=v-(\bar{v}-v) c\left(\gamma^{1}, \gamma^{2}\right)$, in good states one unit of disclosure is worth less than in bad states. Thus, the marginal profit is a decreasing function of the state of nature. With other words, shock and information are strategic substitutes $\left(P_{\gamma v}<0\right)$.

After assessing the effect of the debt level on the best reply functions of the firms, I look for the effect on the equilibrium disclosure. I assume that the disclosure of the firms are strategic complements. It means that one unit of disclosure of one firm is worth more when the disclosure of the other firm is higher: the know-hows "add up" (the best reply curves of the two firms are upward sloping). It is a quite natural assumption if we believe that one of the reasons of forming RJV's is to take advantage of the complementarities of know-how. ${ }^{8}$

Assumption 2.2 The disclosure of the two firms are strategic complements:

$$
S V_{\gamma^{i} \gamma^{j}}^{i}>0 \quad \text { for all }\left(\gamma^{1}, \gamma^{2}\right)
$$

The following proposition establishes the properties of the equilibrium disclosure of the firms when the debt level of any of them increases.

Proposition 2.2 Under Assumption 2.2 the equilibrium disclosure of firm 1 and 2 moves to the same direction if the debt level of one of them increases. In particular:

a) If $P_{\gamma v}>0$, the equilibrium disclosure of the firms $\left(\gamma^{i *}, \gamma^{j *}\right)$ is increasing with $D^{i}$, where $i=1,2$.

\footnotetext{
${ }^{7}$ Though for a different problem, this result is essentially identical with that of Brander and Lewis (1986). They find that higher debt implies higher output.

${ }^{8}$ See Katsoulacos and Ulph (1998) for a discussion about technical substitutability or complementarity between research discoveries.
} 
b) If $P_{\gamma v}=0$, the equilibrium disclosure of the firms $\left(\gamma^{i *}, \gamma^{j *}\right)$ does not depend on the debt levels.

c) If $P_{\gamma v}<0$, the equilibrium disclosure of the firms $\left(\gamma^{i *}, \gamma^{j *}\right)$ is decreasing with $D^{i}$, where $i=1,2$.

The proposition establishes the conditions under which an increase in one firm's debt level makes both firms increase their disclosure, thus increasing the profit of the research joint venture. ${ }^{9}$ Figure 2.2 shows the effect of an increase in $D^{1}$ on the best reply functions of the firms and on the equilibrium disclosure.
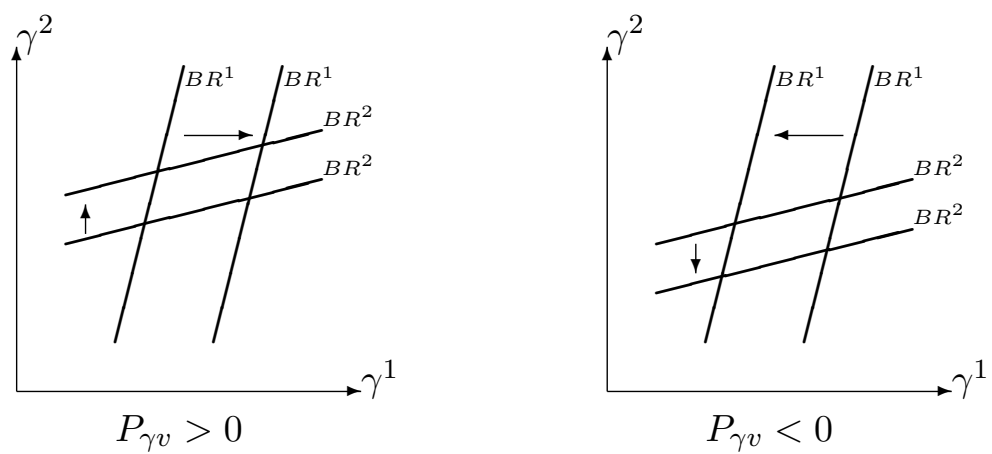

Figure 2.2: Information sharing for changing debt - strategic complements

\subsubsection{Equilibrium debt level}

The previous section gave us the equilibrium disclosure of the firms led by shareholders: $\gamma^{1 *}\left(D^{1}, D^{2}\right)$ and $\gamma^{2 *}\left(D^{1}, D^{2}\right)$. In the first period of the game the shareholders of the firm set the debt $D^{i}$ in order to maximize their income, the equity value plus the money they borrow from the bank. I assume that there is a perfect financial market: the bank lends the same amount as its expected repayment, which is the debt value of the firm. ${ }^{10}$ Therefore, the original equity holders of firm $i$ choose a debt level in the first stage of the game which maximizes the value of the firm, that is is the sum of the equity value $\left(S V^{i}\left(D^{1}, D^{2}\right)\right)$ and the debt value $\left(D V^{i}\left(D^{1}, D^{2}\right)\right)$ :

\footnotetext{
${ }^{9}$ If the know-hows are strategic substitutes (the disclosure of one firm is worth less for higher disclosure of the other) the results are different: equilibrium information transfers move to different direction for an increase in one firm's debt.

${ }^{10}$ The lack of any interest rate only simplifies the analysis, a positive interest rate would give the same qualitative results. Also, as the model is static (although capturing some dynamics through sequential decision making), there is no real meaning associated with the interest rate.
} 


$$
\begin{aligned}
V^{i} & =\int_{\underline{v}}^{\tilde{v}^{i}}\left[\alpha^{i} P\left(v, \gamma^{1 *}, \gamma^{2 *}\right)+B^{i}\left(\gamma^{1 *}, \gamma^{2 *}\right)\right] f(v) d v+\int_{\tilde{v}^{i}}^{\bar{v}} D^{i} f(v) d v+ \\
& +\int_{\tilde{v}^{i}}^{\bar{v}}\left[\alpha^{i} P\left(v, \gamma^{1 *}, \gamma^{2 *}\right)+B^{i}\left(\gamma^{1 *}, \gamma^{2 *}\right)-D^{i}\right] f(v) d v= \\
& =\int_{\underline{v}}^{\bar{v}}\left[\alpha^{i} P\left(v, \gamma^{1 *}, \gamma^{2 *}\right)+B^{i}\left(\gamma^{1 *}, \gamma^{2 *}\right)\right] f(v) d v .
\end{aligned}
$$

Firms decide on the debt level in order to maximize their value. The problem of firm $i$ is:

$$
\operatorname{Max}_{D^{i}} \int_{\underline{v}}^{\bar{v}}\left[\alpha^{i} P\left(v, \gamma^{1 *}\left(D^{1}, D^{2}\right), \gamma^{2 *}\left(D^{1}, D^{2}\right)\right)+B^{i}\left(\gamma^{1 *}\left(D^{1}, D^{2}\right), \gamma^{2 *}\left(D^{1}, D^{2}\right)\right)\right] f(v) d v .
$$

The derivative $V_{D^{i}}^{i}$ for $i=1,2$ (the marginal value of firm $i$ with respect to its debt $D^{i}$ ) determines the optimal debt level, which is described in Proposition 2.3.

$$
V_{D^{i}}^{i}=\frac{d \gamma^{i *}}{d D^{i}} \int_{\underline{v}}^{\bar{v}}\left(\alpha^{i} P_{\gamma^{i}}+B_{\gamma^{i}}^{i}\right) f(v) d v+\frac{d \gamma_{j}^{*}}{d D^{i}} \int_{\underline{v}}^{\bar{v}}\left(\alpha^{i} P_{\gamma^{j}}+B_{\gamma^{j}}^{i}\right) f(v) d v
$$

Proposition 2.3 Under assumption 2.2, the firms' equilibrium debt levels have the following properties:

a) If $P_{\gamma v}>0$, the equilibrium debt levels are positive.

b) If $P_{\gamma v}=0$, the owners of the firms are indifferent about the debt-equity ratio.

c) If $P_{\gamma v}<0$ the equilibrium debt of the firms is zero.

This proposition shows that firms choose positive debt if and only if a higher debt level results in higher disclosure, otherwise they do not take strategic debt. ${ }^{11}$

In the first case, positive debt induces higher disclosure for both firms and the losses of higher own disclosure are smaller than the gains from the other firm's higher information transfer. In case $c$, a higher debt level results in lower equilibrium disclosure and the gains from lower own disclosure are smaller than the losses from the other firm's lower know-how sharing. In order the Modigliani-Miller Theorem to be valid in my setup, the marginal profit of the research joint venture has to be independent of $v$.

\footnotetext{
${ }^{11}$ Note that the result when disclosures are strategic substitutes is the following: when information sharing and the patent value are strategic complements the optimal debt level is zero. When information sharing and the patent value are strategic substitutes the optimal debt level can be positive. So the results are reversed in this case.
} 
Generally, one can assume that higher disclosure results in higher industry profit in the output market. That is, while one firm looses with disclosing a certain amount of know-how, the other firm's gains are higher than this loss. This assumption reflects the usual opinion about the welfare improving nature of disclosure of know-how. In this situation borrowing can increase industry profits, as the following proposition says:

Corollary 2.1 If the sum of the output market profits increases with the disclosure the possibility of debt financing makes the industry better off.

This corollary still holds if we relax the assumption that the optimal level of information transfer was an interior solution. Some studies assume, or some of them derive from their analysis (see for example Pérez-Castrillo and Sandonís, 1996) that firms either share their knowledge entirely or not at all. In that context the possibility of debt financing (under the same assumptions) may change the outcome from "not disclose" to "disclose" while it never changes the outcome to the opposite direction. Thus it still makes the industry better off.

\subsection{Decision on setting up the research joint venture}

In the previous section I assumed that the firms have already decided about signing the cooperative research agreement. This is the adequate scenario when the firms decide on the debt level after having decided to participate in the RJV. In this section I concentrate on the conditions under which the firms agree on the joint research when the debt level is (or can be) decided before the agreement is reached. First the original shareholders of the firm decide on the debt level, then the new equity holders make their decision whether to join the RJV. If they do, in the third stage they disclose the optimal amount of knowledge given the debts. ${ }^{12}$ Figure 2.3 shows the timing of the game.

$\begin{array}{llll} & & & \\ \text { financial } & \text { forming } & \text { information } & \text { profit is } \\ \text { decisions } & \text { the RJV } & \text { disclosure } & \begin{array}{l}\text { realized } \\ \text { (possible bankruptcy) }\end{array}\end{array}$

Figure 2.3: The timing of the RJV decision game

\footnotetext{
${ }^{12} \mathrm{I}$ assume that the amount of debt is not renegotiable. As debt levels are observable, firms might include a punishment in the RJV agreement for decreasing the debt level later.
} 
Throughout this section I assume that the transfer of know-how of the two firms are strategic complements and that the marginal profit of the RJV is increasing with the realization of the shock. That is, I assume that the conditions in part $a$ of Propositions 2.2 and 2.3 hold. ${ }^{13}$

I differentiate between two cases: firms decide on debt levels individually or they can cooperate (sign contracts on debt levels). In the first case the owners of the two firms decide on their debt levels maximizing the value of their own firm. In the second case firms are allowed to sign a contract on debt levels that maximize their joint profits. The possibility of debt financing makes this cooperation feasible: disclosure is not contractible but debt is.

\subsubsection{Firms decide on debt levels individually}

The shareholders of firm $i$ want to enter the RJV after observing the debt levels if the equity value in case of the joint research (determined by the optimal disclosure for the given debt levels) is higher than their profit otherwise. For simplicity I assume that the alternative to joining the RJV is not carrying out the research alone, but not doing it at all. This assumption is supported by two facts. First, in the European competition law the Article 81(3) (former Article 85(3)) allows relatively small firms to sign agreements before setting up a RJV that they do not carry out the proposed joint research alone if they do not go ahead with the RJV. This policy aims to protect small firms from free-riding partners. Second, there are cases when the firms cannot do the research alone because the partner's equipment or expertise is essential for the project. In any case, if the outside option would be individual research the results would be qualitatively the same.

Thus, the shareholders of firm $i$ compare their profit in case of the joint research to their profit without the RJV. These profits are affected by the debt levels set before. The profit from the RJV is influenced in the way described in the previous section. On the other hand, the profit without the joint research project is simply the output market profit with no information sharing less the debt that was taken in the previous stage. That is, the sufficient condition for the shareholders of firm $i$ to participate in the RJV (for the set debt levels $D^{1}, D^{2}$ ) is:

$$
S V^{i *}\left(D^{1}, D^{2}\right) \geq B^{i}(0,0)-D^{i}
$$

\footnotetext{
${ }^{13} \mathrm{I}$ showed in the previous section that otherwise the firms have incentive to choose zero debt level. (Since I have excluded the possibility of "negative debt".) Then the decision is simple: the firms enter the RJV only if $V^{i}\left(D^{1}=0, D^{2}=0\right)>B^{i}\left(\gamma^{1}=0, \gamma^{2}=0\right)$. There is no way to attract the partner with a "promising" high debt level.
} 
The assumption of perfect capital markets ensures that the decision in the second stage is rational also in the first stage. In case of perfect capital markets, condition (2.20) coincides with the following participation constraint in the first stage:

$$
V^{i}\left(D^{1}, D^{2}\right)>B^{i}(0,0)
$$

Let us define the following:

Definition 2.1 Let PS (Participation Set) denote all possible pairs $\left(D^{1}, D^{2}\right)$ such that both firms want to participate. That is, condition (2.21) holds for $i=1,2$. Similarly $P S^{1}$ is the participation set of firm 1 and $P S^{2}$ denotes all pairs of $\left(D^{1}, D^{2}\right)$ for which firm 2 wants to start the joint research activity.

Notice that $P S=P S^{1} \cap P S^{2}$. Moreover, if $(0,0) \notin P S$ the RJV does not start without debt financing.

I describe the firms' interaction through the following game. In the first stage, firms simultaneously choose the amount of debt to take. Then, in the second stage, firm 1 decides whether to offer a RJV agreement to firm 2 (the strategies then are "Y" or "N"). Finally, firm 2 decides whether to accept the offer (the strategies are "Y" or "N"). Naturally, the RJV only starts if firm 1 proposes to firm 2 to investigate together and firm 2 accepts the offer. The sequential decision process of the firms assures that there will not be any dominated equilibrium outcomes. 14

In order to simplify notation, I assume in this subsection that the profit functions of the firms are strictly concave in the debt levels. I also assume that the Nash equilibrium debt levels in the situation where the firms are already in the RJV (i.e. the solution of the problem in $(2.18)$ for $i=1,2)$ are unique and stable. I denote $\left(D^{1 *}, D^{2 *}\right)$ such a solution.

Proposition 2.4 The following strategies are subgame perfect equilibria of the game:

i) If $\left(D^{1 *}, D^{2 *}\right) \in P S$, then $\left\{\left(D^{1 *}, D^{2 *}\right), " Y^{\prime}, " Y^{"}\right\}$.

ii) If $P S=\emptyset$, then $\left\{\right.$ any $\left(D^{1}, D^{2}\right)$, "Y" or "N", "N"\}.

iii) If $P S \neq \emptyset$ and $\left(D^{1 *}, D^{2 *}\right) \in P S^{1}$ but $\left(D^{1 *}, D^{2 *}\right) \notin P S^{2}$, then $\left\{\left(\hat{D}^{1}, D^{2}\left(\hat{D}^{1}\right)\right)\right.$, " $Y^{\prime}$, "Y" $Y^{\text {, where }} \hat{D^{1}}$ is implicitly defined by $V^{2}\left(\hat{D}^{1}, D^{2}\left(\hat{D}^{1}\right)\right)=B^{2}(0,0)$ and $D^{2}\left(\hat{D^{1}}\right)$ is firm 2 's best response for $\hat{D}^{1}$.

\footnotetext{
${ }^{14}$ Furthermore, it seems realistic that firms have several opportunities to change their debt level/offer after observing the other firm's action.
} 
Similarly, if $P S \neq \emptyset$ and $\left(D^{1 *}, D^{2 *}\right) \in P S^{2}$ but $\left(D^{1 *}, D^{2 *}\right) \notin P S^{1}$, then $\left\{\left(D^{1}\left(\hat{D}^{2}\right), \hat{D}^{2}\right)\right.$, "Y", "Y"\}, where $\hat{D}^{2}$ is implicitly defined by $\left.V^{1}\left(D^{1}\left(\hat{D^{2}}\right), \hat{D}^{2}\right)\right)=B^{1}(0,0)$ and $D^{1}\left(\hat{D}^{2}\right)$ is firm 1 's best response for $\hat{D}^{2}$.

In the first case, both firms prefer to form the RJV with debt $\left(D^{1 *}, D^{2 *}\right)$. Consequently, they set these profit maximizing debt levels, firm 1 makes the offer which firm 2 accepts. Therefore, the RJV starts. In the second case, there are no debt pairs for which forming the RJV is preferable. Thus, the firms choose any debt level, and the RJV does not start. In the third case $P S \neq \emptyset$ and $\left(D^{1 *}, D^{2 *}\right) \notin P S$. Now, one firm sets a different debt level than the individually optimal one in order to attract the possible research partner. Note that if the sum of output market profits is increasing with the disclosure this "attractive" debt is higher than the individually optimal $\left(\hat{D}^{i}>D^{i *}\right)$.

Therefore, with the possibility of borrowing, firms may start the cooperative research even if $(0,0) \notin P S$, i.e. when without debt financing the RJV would not be formed. Furthermore, if $(0,0) \in P S$, i.e. the RJV would start anyway, with choosing positive debt firms can commit to higher information transfer. Thus, the possibility of debt financing promotes RJV formation and higher information sharing.

\subsubsection{Firms decide on debt levels together}

If firms can write down a contract on debt levels, they will aim to maximize their joint value:

$$
\operatorname{Max}_{D^{1}, D^{2}} \int_{\underline{v}}^{\bar{v}}\left[p\left(v, \gamma^{1 *}, \gamma^{2 *}\right)+B^{1}\left(\gamma^{1 *}, \gamma^{2 *}\right)+B^{2}\left(\gamma^{1 *}, \gamma^{2 *}\right)\right] f(v) d v
$$

The effect of firm $i$ 's debt level on the joint value is:

$$
\begin{aligned}
\left(V^{i}+V^{j}\right)_{D^{i}} & =\frac{d \gamma^{i *}}{d D^{i}} \int_{\underline{v}}^{\bar{v}}\left[P_{\gamma^{i}}+B^{i}{ }_{\gamma^{i}}+B^{j}{ }_{\gamma^{i}}\right] f(v) d v+ \\
& +\frac{d \gamma^{j *}}{d D^{i}} \int_{\underline{v}}^{\bar{v}}\left[P_{\gamma^{j}}+B^{i}{ }_{\gamma^{j}}+B^{j}{ }_{\gamma^{j}}\right] f(v) d v
\end{aligned}
$$

The sign of this expression is ambiguous, the debts of the contract $\left(D^{1 c}, D^{2 c}\right)$ can be lower or higher than the individually optimal. There can be also zero debt level for one of the firms, which is never optimal individually. However, assuming that the sum of the output market profits increases with the disclosure, (2.23) is always positive, thus the firms are completely debt 
financed (they finance the sunk cost mentioned earlier completely with issuing bonds). In this case, the information share is greater than without the cooperation.

If this kind of contract is possible, the firms always agree on setting up the RJV if $V^{1 c}\left(D^{1 c}, D^{2 c}\right)+$ $V^{2 c}\left(D^{1 c}, D^{2 c}\right)$ is greater than $B^{1}(0,0)+B^{2}(0,0)$. Obviously, under the assumption mentioned above this is always true.

\subsection{Conclusion}

In cooperative research agreements one main input is the firms' own existing know-how. The more information firms share, the higher is the expected profit of the joint venture. But disclosing know-how has a disadvantage if firms are competitors in another market: the research partners can use the knowledge of the other firm in the other market. If one firm shares a part of its know-how, its product market profit decreases, while the other firm gets better off. This creates a moral hazard problem: even when disclosing a certain amount of know-how is preferable for the firms, they cannot contract the information share, thus there is always the possibility of free-riding.

My analysis offers a simple solution. I show that there is connection between the firms' financial structure and their incentives to disclose know-how. This is the consequence of the possibility of bankruptcy: firms are led by shareholders, who are only concerned about the RJV outcomes when the firm does not go bankrupt. So, different debt levels imply different information sharing. Thus, the leverage can be an instrument to alleviate the moral hazard problem.

I also show that the possibility of debt financing can improve welfare in two ways. First, if firms are already in the RJV, their disclosure can be higher by using debt. Second, in some cases there are joint ventures that would not start without the leverage as a commitment.

Finally, I want to mention a possible policy implication. Governments can play an important role: with easily accessed government loans they can make the research joint ventures more attractive, improving welfare at the same time. Of course, firms also prefer this type of external financing because of its tax advantages. So, governments would have to assure that the specific government loans do not give these advantages.

Chapter 4 of my thesis presents an empirical test of the model described above. 
Chapter 3

Cooperative research and firm performance 


\subsection{Introduction}

With the opening of the world economy and increasing competition firms develop new strategies. The new strategies involve more intense networking. Firms engage in cooperative agreements not only with their suppliers and customers but also with their direct competitors. This cooperation takes place in different fields including the distribution, production and research and development phases. The motives of cooperation are cost and risk sharing, access to partners know-how, markets or products. Furthermore, cooperation can bring about efficiency enhancements, such as economies of scale in the production, distribution or $R \& D$ phases or synergy effects from exchanging and/or sharing complementary know-how (Veugelers, 1998).

This paper focuses on cooperation in research and development. Many aspects of cooperative $R \& D$ were studied in the economic literature ${ }^{1}$. The theoretical literature has analyzed extensively how spillovers affect $R \& D$ investment in a cooperative situation compared to competition, and how spillovers influence the profitability and welfare of R\&D cooperation. Furthermore, the theoretical literature deals with stability of research joint ventures, organizational design and asymmetries between research partners.

The importance of research alliances is acknowledged by government policy in various countries. Research joint ventures (RJVs) are granted exemption from anti-trust laws and their formation is encouraged by subsidies.

In the USA the National Cooperative Research Act (1984) and the National Cooperative Research and Production Act (1993) guarantee that every research alliance filed at the Federal Register is evaluated separately if they fail to fulfill antitrust laws. The Clinton administration increased the budget of the Advanced Technology Program that funds collaborative research projects from the private sector to encourage joint research (Branstetter and Sakakibara, 1998).

In Europe Article 81(3) (former 85(3)) of the EC treaty allows the EC Commission to exempt research alliances from Article 81(1) (which prohibits restrictive practices between firms which may affect the trade between the member states or the competition within the EC). In 1985 the Commission granted a block exemption to certain categories of $\mathrm{R} \& \mathrm{D}$ agreements. Moreover, it allows the joint exploitation of the results of that $R \& D$. This exemption is for five years (if the participants are not direct competitors or if they are competitors but the sum of their market shares is less twenty percent). Regulation 151/93 also allows the joint marketing of the product wherever the common market share is less than 10\%. Furthermore, there are also several programs established and funded by the European Commission to promote cooperation in

\footnotetext{
${ }^{1}$ See Veugelers (1998) for a detailed survey.
} 
research. The European Strategic Program for Research in Information Technologies (ESPRIT) is by far the largest of these programs. Between 1983 and 1996 around 9000 organizations participated in over 1200 ESPRIT-financed projects (Lichtenberg, 1996).

In Japan industrial policy actively supported the formation of research consortia since 1959 (Sakakibara, 1997).

Productivity growth, as the engine of economic growth, is one of the main concerns of industrial policy. Research joint ventures are exempt form antitrust laws because they are considered to promote efficiency. This can be either productive efficiency or other types, like $R \& D$ cost sharing. Also, as we saw before one of the reasons why firms form RJVs is to gain efficiency. This is why analyzing the effects of research joint venture participation on productivity is an interesting issue.

Evaluating the overall benefits of cooperative research is very difficult because the cooperation may have an impact both on $R \& D$ spending and the competitive structure of the industry. Firms that are cooperating in research and development might be inclined to do so even in the product market competition, a behaviour that should concern antitrust authorities.

Geroski (1992) summarizes the theoretical findings on this topic. He concludes that R\&D ventures are desirable whenever technological spillovers and positive pecuniary externalities (risk sharing) exist. Also, a non-exclusive consortia which operates between firms with complementary skills and products that undertakes pro-competitive research is preferable to a cooperative research agreement between firms on the same output market.

Following Geroski's argument, when evaluating the impact of cooperative R\&D we have to separate its direct effect on productivity and its indirect effect through research intensity and competition. How does cooperation in R\&D affect productivity? R\&D output is considered to have a positive effect on productivity (many times this output is a new process which allows lower unit costs in production). In case of joint research, the research productivity is affected. So, the same amount of $R \& D$ investment results in more (or less) innovation. Then, if the competitive structure and firms' R\&D investments are unaffected, cooperation in innovative activities increases (decreases) productivity compared to the competitive R\&D case.

This direct effect of joint research and development is studied by Kamien et al. (1992), Beath et al. (1998) and Baumol (1999). The common feature of their analysis is that they model process innovation (cost reduction).

Kamien et al. (1992) present an oligopoly model with spillovers where firms compete either à la Cournot or à la Bertrand in the product market. They examine R\&D performance and welfare 
in four different research scenarios. They find that a research joint venture that cooperates in its R\&D decisions yields the lowest unit cost with lower research intensities under Cournot competition, and, in most cases, under Bertrand competition. Diminishing returns in the R\&D production function are crucial in their model.

Beath et al. (1998) present a non-tournament model of process innovation with spillovers in the R\&D process and with a Cournot duopoly in the output market. They explicitly model the innovation as a two stage process where in the first stage the knowledge is produced and in the second stage this knowledge is employed to reduce unit cost. They distinguish between simple and complementary research paths. The research process, like in Kamien et al. (1992) exhibits diminishing returns (either in the first or in the second stage). They show that in the case of a simple research path the RJV only operates one research lab and gets the same cost reduction cheaper than in the competitive case. In case of complementary research paths the RJV either operates one or two research labs, depending where diminishing returns occur in the innovation process, and the level of cost reduction is at least as high as in the competitive case with spending less in the RJV than the sum of the two firms spending separately.

Baumol (1999), on the other hand finds in a Cournot oligopolistic setting where research outputs are complementary that when the number of cooperating firms increases, each firms' unit cost decreases but with an increase in $R \& D$ investment. Thus, the implications of cooperation for productivity are ambiguous.

The very few empirical papers are centered around the motives for participation in research consortia. Only a handful of the studies evaluate the performance of participating firms. The performance measures used in these papers are research intensity (Roller et al, 2000), profitability (Siebert 1997) and stock market valuation (Sleuwagen et al., 1995 and Scott, 1996). Surprisingly, only very little attention was paid to the impact of joint $R \& D$ on productivity ${ }^{2}$. The only exceptions I know of are the studies by Irwin and Klenow (1996) about the labor productivity of Semantech firms, and Branstetter and Sakakibara (1998) about the research productivity of Japanese research consortia. The authors of both studies estimate the effect of participation in government sponsored $\mathrm{R} \& \mathrm{D}$ consortia.

Irwin and Klenow (1996) evaluated the SEMATECH program in the US. SEMATECH was set up to conduct research and development for manufacturing semiconductor products. The consortium was set up in 1987 and enjoyed government subsidies between 1987-1996. Irwin and Klenow used a panel of firm level variables for the period 1970-1993. They found that the

\footnotetext{
${ }^{2}$ The general lack of time-series dimension in the data makes it difficult for researchers to carry out productivity studies, because they cannot really control for fixed effects and possible endogeneity.
} 
SEMATECH firms spent less on research and had higher sales growth than non-participating firms. On the other hand, they did not find significant difference between non-member and member firms in terms of labor productivity growth, physical investment and returns on assets. A weak point of their analysis was the control group they used. The fixed effects model they used controlled for permanent differences in firm performance but it did not correct for the possible endogeneity in the response for SEMATECH participation: that the distribution of the parameter of the participation dummy may differ systematically for participating and nonparticipating firms.

Branstetter and Sakakibara (1998) conducted a microeconometric analysis of Japanese research consortia. They found that government sponsored R\&D consortia participation increased R\&D spending. Moreover, they found that participating firms had higher research productivity than other firms. They measured research output by the number of patents. They controlled for the possible endogeneity in the response for participation in a RJV. Following the logic outlined in the previous section, increased research productivity means a positive direct effect of joint research on productivity.

In this paper I study the productivity implications of research joint venture participation using a large panel of European, Japanese and US companies. Furthermore, using a sample of around 1500 US firm with available information on R\&D spending I separate the effect of total R\&D investment and RJV participation on productivity. Using the generalized method of moments estimation technique developed by Arellano and Bond I control for the possible endogeneity of the independent variables. I find evidence that joint R\&D increases productivity. The result is similar even when the effect through $R \& D$ investment is separated. The results suggest that when $R \& D$ spending is controlled for it is the horizontal form of $R \& D$ cooperation that brings about the most significant productivity improvement. This is consistent with the findings of the theoretical literature that cost-sharing is an important incentive in forming horizontal research consortia.

In the next sections I describe the empirical investigation. In section 3 I discuss the results of the analysis. Section 4 concludes. 


\subsection{Empirical investigation}

\subsubsection{The model}

Consider the following log-linear Cobb-Douglas production function:

$$
\begin{aligned}
y_{i t}= & \lambda y_{i, t-1}+(1-\lambda) \beta_{n} n_{i t}+(1-\lambda) \beta_{k} k_{i t}+\alpha r_{i t}+\gamma_{t}+\eta_{i}+\epsilon 1_{i t}+m_{i t} \\
& \epsilon 1_{i t} \sim M A(0)
\end{aligned}
$$

Where $y_{i t}$ is the log output of firm $i$ in year $t, n_{i t}$ is log employment and $k_{i t}$ is log capital stock. The term $r_{i t}$ stands for the log R\&D output (result of R\&D) of the firm $i$. The term $\gamma_{t}$ is a year specific intercept, $\eta_{i}$ is an unobservable firm specific effect, $\epsilon 1_{i t}$ is a productivity shock and $m_{i t}$ is measurement error. In case of constant returns to scale $\beta_{n}+\beta_{k}=1$, but this is not necessarily imposed. The inclusion of the lagged output is the simplest way of describing the fact that it takes some time for the output to reach its new long run level whenever the inputs change. The inclusion of this lag also supports the assumption on the serially uncorrelated productivity shocks (Nickell (1996) considers the same production function).

To analyze the role of research joint venture participation I assume that the R\&D production function is the following:

$$
\begin{aligned}
R_{i t}= & R D_{i, t-1}^{\mu} e^{\nu R J V_{i, t-1}} e^{\epsilon 2_{i t}} \\
& \epsilon 2_{i t} \sim M A(0)
\end{aligned}
$$

where $R_{i t}$ is the output (result) of research and development, $R D_{i, t-1}$ is the $\mathrm{R} \& \mathrm{D}$ stock of the company, $R J V_{i, t-1}$ is the number of research joint ventures the firm participates in and $\epsilon 2_{i t}$ is a research productivity shock. Thus, the output of innovative activity depends on the R\&D spending and on an R\&D productivity term. This research productivity term depends on the number of cooperative research agreements. ${ }^{3}$ The lagged levels of R\&D stock and RJV participation refer to the fact that their effect on research output is not immediate. I also estimate the equation with earlier lags of the RJV participation.

Taking the logarithm of equation (3.2) results in a simple log-linear form:

$$
r_{i t}=\mu r d_{i, t-1}+\nu R J V_{i, t-1}+\epsilon 2_{i t} .
$$

\footnotetext{
${ }^{3}$ This way of modeling the innovation process is very similar to the one used by Branstetter and Sakakibara (1998)
} 
Introducing (3.3) into (3.1) and rearranging the resulting equation we get:

$$
y_{i t}=\pi_{1} y_{i, t-1}+\pi_{2} n_{i t}+\pi_{3} k_{i t}+\pi_{4} R J V_{i, t-1}+\pi_{5} r d_{i, t-1}+\gamma_{t}+\eta_{i}+\omega_{i t}
$$

Notice that the error term $\left(\omega_{i t}=\epsilon 1_{i t}+\alpha \epsilon 2_{i t}+m_{i t}\right)$ follows an MA(0) process if there is no measurement error. In the presence of measurement error this process can be different from MA(0), depending on the marginal process of $m_{i t}$.

\subsubsection{Estimation}

To eliminate the firm specific effect I take first differences of the equation in (3.4).

Thus, the benchmark equation I estimate is the following:

$$
\begin{aligned}
\Delta y_{i t}= & \pi_{1} \Delta y_{i, t-1}+\pi_{2} \Delta n_{i t}+\pi_{3} \Delta k_{i t}+\pi_{4} \Delta R J V_{i, t-1}+\pi_{5} \Delta r d_{i, t-1}+ \\
& +\pi_{6} \text { year }+\omega_{i t}
\end{aligned}
$$

Notice that with this specification the coefficient of the $R J V$ term measures the total effect of cooperative research net of the effect of change in $R \& D$ investment on productivity. On the other hand, omitting the $r d$ variable $\pi_{4}$ measures the total effect of RJV participation on productivity. ${ }^{4}$

Note that constant returns to scale would mean that the sum of $\pi_{1}, \pi_{2}$ and $\pi_{3}$ is equal to 1 . I will also present result when CRS is imposed.

The values of employment, capital stock, research joint venture participation, R\&D stock and lagged sales are possibly correlated with the error term and the firm specific effect. However, assuming the usual initial conditions $\left(E\left(x_{i 1} \omega_{i t}\right)=0\right.$ for $t=2,3, \ldots, T$ where $x_{i 1}$ represents the endogenous regressors) to hold, in the absence of measurement error all the lagged levels of these regressors beyond $t-1$ can be used as instruments after first differencing to eliminate the firm specific effect. The crucial assumption is the absence of serial correlation. This will be tested.

However, there is a possible problem: if the marginal processes for the endogenous variables are highly persistent the lagged levels can be weakly correlated with the subsequent first differences. In this case the GMM estimator has been found to have poor finite sample properties (Blundell and Bond, 1998), therefore the use of system GMM estimator can be recommended. However, in the analysis presented in this paper this does not seem to be a problem.

\footnotetext{
${ }^{4}$ Note that if RJV participation and $R \& D$ expenditure are correlated, then omitting the $R \& D$ variable may simply imply that the coefficient of the RJV participation reflects R\&D influencing productivity.
} 


\subsubsection{Data}

The data come from different sources. The information about research consortia comes from the SDCA-SDC Worldwide Joint Ventures \& Alliances database. ${ }^{5}$ This database has information about transactions valued at least 1 million USD between 1985-1992 and transactions of any value after $1992 .{ }^{6}$ Since this database has only scarce information about the characteristics of the participating firms I merged it with other databases, which include firm level accounting data in a panel structure. The databases used for the matching are Global Vantage and Compustat. ${ }^{7}$ The Global Vantage database contains accounting data for large firms worldwide. The Compustat database has information about (mainly listed) North-American companies.

The merged database contains around 20,000 firms in a panel structure between 1985-1995 worldwide. There are around 900 firms that participate in R\&D alliances. However, in this paper I use a subsample of European, Japanese and US firms. Due to missing observations I also eliminated many firms. The dataset used in this paper contains an unbalanced panel of around 6200 firms for the period 1985-1995. This database is biased towards large firms. The Appendix B presents descriptive statistics of the sample and subsamples used for the analysis.

The Global Vantage and Compustat databases contain worldwide information (output, employment, etc.) about firms. This is why I used the ultimate parent of firms in the SDCA-SDC database to merge with the above the databases.

The variables used in the estimations are the following:

Output, as a proxy I use net real sales. Other possibility would be to construct a measure of value added using the wage bill, pre-tax profits, interest payments and depreciation. However, the reported profits can be different from the true ones, so this measure may not be reliable (see Nickell, 1996).

Employment, the variable measures the full-time, part-time and seasonal employment.

Capital, I proxy capital stock with real total assets.

$R E D$ stock, this variable is constructed using the real $\mathrm{R} \& \mathrm{D}$ expenditures of firms and a 0.15 depreciation rate. I assume that before the beginning of the sample period the growth rate of R\&D investment was the same as the average growth rate in the sample period. Where this is not available, I assume a $5 \%$ growth rate. This variable is missing in many observations, mainly in Europe where firms are not legally required to disclose R\&D expenditure. This is

\footnotetext{
${ }^{5}$ Thanks to Bruno Cassimann and the TSER Project SOE1-CT97-1059 for providing the data.

${ }^{6}$ For years after 1992 I only use data about alliances with transaction values greater than 1 million USD.

${ }^{7}$ Thanks to the IFS for the data.
} 
why I show results with and without this variable. For the US I have information whether the R\&D expenditure contains a government subsidy. But using this extra information does not add to the analysis since firms decide about their optimal $R \& D$ investment internalizing this subsidy. On the other hand, this information can be useful when assessing firms' incentives to form research consortia.

$R J V$ participation, the variable contains the number of research joint ventures the firm has joined since 1985. Since there is no information about research consortia participation before 1985, the levels of this variable may contain serious measurement error. This is not a problem in the first differenced equation but it is not possible to use system-GMM as this requires information about levels. Also, the information contained in this variable constrains the possible functional forms of the R\&D production function I can consider. I cannot use the logarithm of this variable since I do not know the levels. In some specifications I distinguish among three type of research joint ventures. I define horizontal RJVs as joint research between firms in industries with the same 2-digit SIC code. Similarly, vertical RJVs consist of firms from different 2-digit SIC industries. Vertical consortia that have a university participant are treated separately. Note that there might be incorrectly classified RJVs. Firstly, within a 2-digit SIC industry there might be vertical relationship between RJV participant. However, had I used 3-digit SIC codes for the definition I might have classified horizontal RJVs as vertical. Secondly, I use primary SIC codes for the definition. Some firms might have small businesses in other industries and the RJV participant might be one of these businesses with different 2-digit SIC code. Thus, my method would not classify these RJVs correctly.

Appendix B presents detailed descriptive statistics of the above variables.

\subsection{Results}

I have performed estimation on three different samples. The first sample contains all US, European and Japanese firms. The second sample is constrained to US firms. The third sample is a subsample of US firms with declared R\&D spending. As production is likely to have different characteristics in different regions, I do not necessarily expect strong results on the mixed sample. However, these results might support the robustness of the results of the US sample.

Table 3.1 contains the main results for the mixed (USA, Japan and Europe) sample. The first two columns contain results without imposing constant returns to scale. The third column shows the results for the same sample as in the second column imposing CRS. ${ }^{8}$ In Table 3.1 the

\footnotetext{
${ }^{8}$ When imposing CRS the DPD98 program uses one more lag when constructing the variables. Consequently
} 
total effect of RJV participation on productivity is measured, i.e. R\&D intensity and change in the competitive structure are not controlled for.

Table 3.2 shows results for the same specifications as Table 3.1 for a subsample of US firms.

Table 3.3 shows results for a subsample of US firms with information about R\&D spending. Here I investigate the effects of cooperative research on productivity net of R\&D effects.

Table 3.4 differentiates among the three types of research joint ventures. The table refers to the US subsample with $\mathrm{R} \& \mathrm{D}$ data as this is the only sample that allows me to investigate the net RJV effect.

Table 3.5 shows the results for introducing earlier lags of RJV participation into the estimated equation. For this exercise I use the US subsample that proved to be more reliable than the mixed sample.

\subsubsection{Total RJV effect}

The instruments in the first two columns of Table 3.1 are valid (although only marginally). In these columns negative first order serial correlation is accepted. Second order serial correlation is rejected. This is in accordance with the assumptions and taking first differences.

In the specification of the third column there is evidence for second order serial correlation. This does not validate the use of the GMM method. Consequently, the results are not reliable. This is consistent with the fact that constant returns to scale are rejected $(\mathrm{F}(2,26201)=1220.151)$.

In all columns there is a positive sign associated with the coefficient of the $R J V$ variable. In the first column the coefficient is significant on the $10 \%$ level. Thus, in the mixed sample there is evidence that RJV participation significantly improves productivity.

In Table 3.2 the same exercise is repeated with the same qualitative results. Thus, CRS are rejected $^{9}$ and there is evidence for the productivity-enhancing effect of RJV participation. This sample seems to be more robust than the mixed sample, the change in sample size influences significance on a lesser scale.

The size of the RJV effect in the US sample is marginally larger than in the mixed sample (one additional cooperative research agreement increases output by around 1\%).

firms with only three consecutive observations are dropped. In column 2 I use this subsample in the nonconstrained specification to obtain fully comparable results.

${ }^{9} \mathrm{~F}(2,16090)=322.934$. 
Table 3.1: Impact of RJV participation on productivity (1985-1995), mixed sample

\begin{tabular}{lccc}
\hline \hline Independent variables & I & II & III \\
\hline$y_{i, t-1}$ & .431 & .465 & .291 \\
& $(12.84)$ & $(9.26)$ & $(6.91)$ \\
$n_{i t}$ & .263 & .211 & .300 \\
& $(3.84)$ & $(2.09)$ & $(2.55)$ \\
$k_{i t}$ & .342 & .377 & .409 \\
& $(7.56)$ & $(5.58)$ & \\
$R J V_{i, t-1}$ & .007 & .003 & .006 \\
& $(1.76)$ & $(.98)$ & $(1.63)$ \\
\hline $1^{\text {st }}$ serial corr & -7.5 & -5.9 & -7.1 \\
(p-value) & $(.00)$ & $(.00)$ & $(.00)$ \\
$2^{\text {nd }}$ serial corr & -.1 & -.3 & -3.6 \\
(p-value) & $(.96)$ & $(.80)$ & $(.00)$ \\
Sargan-test & 35.2 & 33.0 & 50.3 \\
degrees of freedom & 16 & 14 & 14 \\
(p-value) & $(.01)$ & $(.01)$ & $(.00)$ \\
\hline Number of obs. & 32428 & 26213 & 26213 \\
Number of firms & 6215 & 5517 & 5517 \\
\hline
\end{tabular}

Instruments used in the first two columns are $y_{t-2}$ and $n_{t-2}$, while in the third column $y_{t-3}$ and $n_{t-3}$ are used. Capital is treated as strictly exogenous in all columns. In the first two columns results are qualitatively the same when including further lags as instruments. Equations were estimated using the DPD98 package written by Arellano and Bond. All three estimations include jointly significant time dummies. The table reports consistent one-step estimators that are robust to heteroskedasticy of general form. The two step (fully efficient) estimators are not reported, because Arellano and Bond (1991) indicate that standard errors are overstatedly low in this case (t-values are in parentheses). 
Table 3.2: Impact of RJV participation on productivity (1985-1995), USA

\begin{tabular}{lccc}
\hline \hline Independent variables & I & II & III \\
\hline$y_{i, t-1}$ & .437 & .449 & .274 \\
& $(11.35)$ & $(8.18)$ & $(8.84)$ \\
$n_{i t}$ & .394 & .431 & .448 \\
& $(4.52)$ & $(3.21)$ & $(2.53)$ \\
$k_{i t}$ & .243 & .219 & .278 \\
& $(3.78)$ & $(2.31)$ & \\
$R J V_{i, t-1}$ & .011 & .007 & .010 \\
& $(1.98)$ & $(1.74)$ & $(1.63)$ \\
\hline $1^{\text {st }}$ serial corr & -5.9 & -4.8 & -6.1 \\
(p-value) & $(.00)$ & $(.00)$ & $(.00)$ \\
$2^{\text {nd }}$ serial corr & -.1 & -.1 & -2.9 \\
(p-value) & $(.89)$ & $(.94)$ & $(.00)$ \\
Sargan-test & 16.8 & 13.5 & 7.8 \\
degrees of freedom & 16 & 14 & 14 \\
(p-value) & $(.40)$ & $(.49)$ & $(.90)$ \\
\hline Number of obs. & 19258 & 16102 & 16102 \\
Number of firms & 3156 & 2894 & 2894 \\
\hline
\end{tabular}

Instruments used in the first two columns are $y_{t-2}$ and $n_{t-2}$, while in the third column $y_{t-3}$ and $n_{t-3}$ are used. Capital is treated as strictly exogenous in all columns. In all columns results are qualitatively the same when including further lags as instruments. Equations were estimated using the DPD98 package written by Arellano and Bond. All three estimations include jointly significant time dummies. The table reports consistent one-step estimators that are robust to heteroskedasticy of general form. The two step (fully efficient) estimators are not reported, because Arellano and Bond (1991) indicate that standard errors are overstatedly low in this case (t-values are in parentheses). 
Of course, one should keep in mind that these results show only the total effect: changes in the competitive structure and $\mathrm{R} \& \mathrm{D}$ investment are not controlled for.

To further improve the estimation results, it would be useful to include nonlinear effects of the RJV participation. However, as the level of RJV participation is biased, the results will not necessarily be reliable.

\subsubsection{Direct RJV effect}

I have constructed a subsample where the firm's R\&D spending can be controlled for to investigate the relation between the direct and indirect effects of research joint venture participation. As the descriptive statistics in the Appendix show, this subsample has data about the larger firms in the USA sample. The data in this subsample allows us to control for possible correlation between research joint venture participation and $R \& D$ spending. Thus, we can calculate the effect of joint research of productivity net of any additional R\&D effect. Note that the effects of change in the competitive structure of the industry as a result of cooperative research are not controlled for. Thus, the results are to be interpreted with caution.

The results are shown in Table 3.3. In all three specifications first order serial correlation is accepted and second order serial correlation is rejected and the instruments are valid. All variables are significant.

The first column shows the total effect of joint research on output. In the second column the coefficient of the RJV variable shows the total effect net the indirect effect through $R \& D$ spending. In the last column only $\mathrm{R} \& \mathrm{D}$ expenditure is introduced to investigate the robustness of the results.

The results show that the effect of RJV participation is not diminished when controlling for R\&D spending. This suggests that the magnitude of the total effect of RJV participation does not reflect an increase in research expenditure but rather an increase in research productivity. When the different types of RJV's are treated separately this results changes as can be seen in table $3.4 .^{10}$

\footnotetext{
${ }^{10}$ This finding is consistent with the results of Rõller et al. (1997). They found no evidence that RJV participation influences R\&D spending when not controlling for different types of research consortia.
} 
Table 3.3: Impact of RJV participation on productivity (1985-1995), USA

\begin{tabular}{lccc}
\hline \hline Independent variables & I & II & III \\
\hline$y_{i, t-1}$ & .390 & .228 & .239 \\
& $(5.31)$ & $(2.19)$ & $(2.26)$ \\
$n_{i t}$ & .479 & .531 & .488 \\
& $(4.15)$ & $(3.53)$ & $(3.19)$ \\
$k_{i t}$ & .195 & .189 & .214 \\
& $(2.59)$ & $(2.26)$ & $(2.55)$ \\
$R J V_{i, t-1}$ & .012 & .012 & \\
& $(1.83)$ & $(2.00)$ & \\
$R \& D_{i, t-1}$ & & .157 & .157 \\
& & $(1.66)$ & $(1.67)$ \\
\hline $1^{\text {st }}$ serial corr & -3.8 & -3.2 & -3.2 \\
(p-value) & $(.00)$ & $(.00)$ & $(.00)$ \\
$2^{\text {nd }}$ serial corr & 1.4 & 1.5 & 1.5 \\
(p-value) & $(.16)$ & $(.13)$ & $(.13)$ \\
Sargan-test & 22.0 & 52.3 & 51.6 \\
degrees of freedom & 16 & 30 & 30 \\
(p-value) & $(.14)$ & $(.01)$ & $(.01)$ \\
\hline Number of obs. & 9290 & 9290 & 9290 \\
Number of firms & 1574 & 1574 & 1574 \\
\hline & & &
\end{tabular}

Instruments used in the first column are $y_{t-2}$ and $n_{t-2}$ while in the second and third columns $y_{t-3}, y_{t-4}$, $n_{t-2}$ and $R \& D_{t-2}$ are used. Capital is treated as strictly exogenous in all columns. The results are qualitatively the same when including further lags as instruments. The equations were estimated using the DPD98 package written by Arellano and Bond. All three estimations include jointly significant time dummies. The table reports consistent one-step estimators that are robust to heteroskedasticy of general form (t-values are in parentheses). 


\subsubsection{Vertical and horizontal research joint ventures}

In Table 3.4 I distinguish among the different types of research consortia. I treat separately horizontal and vertical research joint ventures. Horizontal research joint ventures ( $H R J V)$ are formed exclusively between firms that compete on the output market. I define vertical research joint ventures $(V R J V)$ as research consortia with at least one participant that is not a competitor of the others. Furthermore, I form a third category that includes all those (vertical) RJVs that have at least one university participant $(U R J V)$.

The first column contains the same estimation result as the first column of the previous table. This indicates that when the R\&D stock is not controlled for participation in a RJV increases productivity. The RJV variable is significant on the $10 \%$ level.

In the second column the three different types of research consortia participation are introduced rather than a single RJV variable. The result shows that research cooperation with universities decreases productivity on the short run. This is consistent with the fact that such research joint ventures engage rather in basic research that will give results on the long run at the same time taking resources (money and personnel) from more commercially oriented research. The positive coefficients of the other two types of RJVs are not significant.

The most interesting result is included in the third column. Once the R\&D stock of the companies is controlled for the sign of the $U R J V$ variable and its significance level practically does not change. However, the coefficient associated with participation in horizontal RJVs increases and becomes significant on the $5 \%$ level! This clearly indicates that when competitors form a research consortium their productivity increases. Moreover, this increase might be partly offset by a decrease in $R \& D$ spending. This result gives indirect evidence for the cost sharing hypothesis of the horizontal research joint ventures.

\subsubsection{Different lags of the RJV participation}

Using the first lag of the RJV participation variable is questionable. We do not have any information about the time-span of the impact of cooperative research on productivity. Many times the cooperation is only the exchange of the already existing know-how (for example the research aims to find the correct shape of the product of one firm that can be used in the machine of the other). On the other hand, cooperative research between firms and universities often involve basic research, which has its returns only on the long run.

The length of the panel does not allow for using early lags. This is why I decided to investigate the effects of introducing only the second lag of RJV participation in addition. The results show 
Table 3.4: Impact of RJV participation on productivity (1985-1995), USA

\begin{tabular}{|c|c|c|c|}
\hline Independent variables & $\mathrm{I}$ & II & III \\
\hline \multirow{2}{*}{$y_{i, t-1}$} & .390 & .391 & .229 \\
\hline & $(5.31)$ & $(5.32)$ & $(2.20)$ \\
\hline \multirow[t]{2}{*}{$n_{i t}$} & .479 & .478 & .531 \\
\hline & $(4.15)$ & $(4.15)$ & $(3.54)$ \\
\hline \multirow[t]{2}{*}{$k_{i t}$} & .195 & .195 & .189 \\
\hline & $(2.59)$ & $(2.60)$ & $(2.27)$ \\
\hline \multirow{2}{*}{$R J V_{i, t-1}$} & .012 & & \\
\hline & $(1.83)$ & & \\
\hline \multirow[t]{2}{*}{$V R J V_{i, t-1}$} & & .011 & .009 \\
\hline & & $(1.50)$ & $(1.14)$ \\
\hline \multirow[t]{2}{*}{$H R J V_{i, t-1}$} & & .016 & .022 \\
\hline & & $(1.13)$ & $(1.97)$ \\
\hline \multirow{2}{*}{$U R J V_{i, t-1}$} & & -.104 & -.096 \\
\hline & & $(-2.72)$ & $(-2.52)$ \\
\hline \multirow[t]{2}{*}{$R \& D_{i, t-1}$} & & & .157 \\
\hline & & & $(1.67)$ \\
\hline $1^{\text {st }}$ serial corr & -3.8 & -3.85 & -3.2 \\
\hline (p-value) & $(.00)$ & $(.00)$ & $(.00)$ \\
\hline $2^{\text {nd }}$ serial corr & 1.41 & 1.41 & 1.52 \\
\hline (p-value) & $(.16)$ & $(.16)$ & $(.13)$ \\
\hline Sargan-test & 22.2 & 22.2 & 52.3 \\
\hline degrees of freedom & 14 & 16 & 30 \\
\hline (p-value) & $(.14)$ & $(.14)$ & $(.01)$ \\
\hline Number of obs. & 9290 & 9290 & 9290 \\
\hline Number of firms & 1574 & 1574 & 1574 \\
\hline
\end{tabular}

Instruments used in the first two columns are $y_{t-2}$ and $n_{t-2}$ while third column $y_{t-3}, y_{t-4}, n_{t-2}$ and $R \& D_{t-2}$ are used. Capital is treated as strictly exogenous in all columns. The results are qualitatively the same when including further lags as instruments. The equations were estimated using the DPD98 package written by Arellano and Bond. All three estimations include jointly significant time dummies. The table reports consistent one-step estimators that are robust to heteroskedasticy of general form (t-values are in parentheses). 
Table 3.5: Total impact of RJV participation on productivity (1985-1995)

\begin{tabular}{lccc}
\hline \hline Independent variables & I & II & III \\
\hline$y_{i, t-1}$ & .449 & .447 & .449 \\
& $(8.18)$ & $(8.17)$ & $(8.17)$ \\
$n_{i t}$ & .431 & .420 & .430 \\
& $(3.21)$ & $(3.15)$ & $(3.20)$ \\
$k_{i t}$ & .219 & .227 & .220 \\
& $(2.31)$ & $(2.41)$ & $(2.32)$ \\
$R J V_{i, t-1}$ & .009 & & .010 \\
& $(1.74)$ & & $(1.40)$ \\
$R J V_{i, t-2}$ & & .002 & -.004 \\
& & $(.32)$ & $(-.52)$ \\
\hline $1^{\text {st }}$ serial corr & -4.8 & -4.8 & -4.8 \\
(p-value) & $(.00)$ & $(.00)$ & $(.00)$ \\
$2^{\text {nd }}$ serial corr & -.1 & -.1 & .1 \\
(p-value) & $(.94)$ & $(.96)$ & $(.94)$ \\
Sargan-test & 13.5 & 13.5 & 13.6 \\
degrees of freedom & 14 & 14 & 14 \\
(p-value) & $(.49)$ & $(.49)$ & $(.48)$ \\
\hline Number of obs. & 16102 & 16102 & 16102 \\
Number of firms & 2894 & 2894 & 2894 \\
\hline & & &
\end{tabular}

Instruments used are $y_{t-2}$ and $n_{t-2}$ while capital is treated strictly exogenous in all columns. The results are qualitatively the same when including further lags as instruments. The equations were estimated using the DPD98 package written by Arellano and Bond. All three estimations include jointly significant time dummies. The table reports consistent one-step estimators that are robust to heteroskedasticy of general form (t-values are in parentheses). 
that participation in an additional research joint venture altogether increases productivity (the sum of the coefficients of the first and second lags is positive and jointly significant). Also, the effect in one year is more important (and significant) than in two years.

This suggests that joint research increases productivity within a year. This observation supports the theory that firms in RJVs learn from each other. Thus, even if a specific project will produce results over a longer period, firms can use the know-how learnt from their partners in their individual production processes.

\subsection{Conclusion}

Using a sample of around 6200 firms I estimated the effect of research joint venture participation on productivity. I found evidence that joint research improves productivity. This result supports the industrial policy of governments, which encourages the formation of research consortia.

I also found indirect evidence that an important reason for forming horizontal research joint ventures is to share costs. In the next chapter I present direct evidence for this. 
Chapter 4

Incentives to form horizontal research joint ventures 


\subsection{Introduction}

For the last two decades industrial policies both in the United States and Western Europe have encouraged cooperative research and development. In Japan firms have been participating in government sponsored research consortia since the beginning of the 1960's. Research joint ventures (RJVs) are seen as tools to share risk and cost between firms and to overcome the appropriability problem caused by involuntary spillovers.

There is a large body of theoretical literature dealing with several aspects of research joint ventures. ${ }^{1}$ A substantial part of these papers analyzes firms' incentives to engage in cooperative research and the characteristics of firms that participate in research consortia. Most of the theoretical literature have concentrated on internalizing spillovers through research joint ventures and share the costs of cooperative research. Kamien, Muller and Zang (1992) find that in industries where involuntary spillovers are high, the private incentives of firms to conduct research and development are diminished. In these industries, firms that form an all-encompassing RJV increase there $R \& D$ spending. However, in industries where the returns of $R \& D$ are easy to appropriate, participation in a cooperative research venture might imply the opposite effect: firms reduce their R\&D spending because they share the costs of innovation. ${ }^{2}$

The main focus of the empirical literature is the analysis of the incentives to form research consortia. Tyler and Steensma (1995) describe the motives that top executives consider when deciding to form a research corporation. They provide evidence for the importance of cost and risk sharing for the success of R\&D cooperation. Scott (1996) studies how different factors influence the probability of cooperation on a sample of large R\&D intensive US private firms that do emissions-reducing process $R \& D$. He concludes that firms with higher $R \& D$ spending are more likely to participate in joint research to reduce emissions. Moreover, firms are more likely to cooperate when appropriability of the results is more difficult. He also finds that import competition as well as industry concentration reduces the probability of cooperation. Furthermore, although the pursuit of efficiency from larger projects and company size do not seem to be important, more risky projects are more likely to be carried out jointly.

Sakakibara (1997) compares two motives: cost-sharing and skill-sharing. She analyzes under which circumstances is one or the other more important using a sample of Japanese governmentsponsored R\&D consortia. She finds that the skill sharing motive is relatively more important in R\&D consortia where the participants possess more heterogeneous capabilities. The importance of the cost sharing motive seems to be more important when participants have homogeneous

\footnotetext{
${ }^{1}$ See Veugelers 1998 for a comprehensive description of theoretical and empirical studies.

${ }^{2}$ Katz (1986) and d'Aspremont and Jacquemin (1988) find similar results.
} 
capabilities and the project size is large. Sakakibara (2001) finds that R\&D cooperation formed by firms with more heterogeneous capabilities is associated with higher R\&D spending.

Rõller, Tombak and Siebert (2000) analyze how different motives influence the probability that two firms sign cooperative agreements with each other in a sample of cooperating firms. Their results indicate that a significant factor in determining whether two firms join in an RJV is that they are similar in size. Moreover, they find evidence that the cost sharing motive is important. The existence of spillovers influences the probability of two firms to cooperate only in some of the industries.

Cassiman and Veugelers (1998) analyze how different motives affect the probability of cooperation on a sample of innovating Belgian firms. They distinguish between incoming (information sharing) and outgoing (involuntary information transfer) spillovers. They claim that spillovers are firm specific. They find that firms facing cost barriers are more likely to innovate jointly and the risk sharing motive does not seem to be very important. Larger firms are more likely to cooperate. Incoming spillovers have a positive effect on cooperation, outgoing spillovers have a negative (the better is the legal and strategic protection, the higher is the probability to cooperate). They also study different types of cooperation: vertical cooperation and cooperation with research institutes. In case of cooperating with research institutions, both risk and cost sharing seem to be important. In case of vertical cooperation, neither cost nor risk sharing are important, but the search for external know-how and complementarities seem to be crucial. Incoming spillovers matter only in the cooperation with research institutes while in the other case outgoing spillovers are important. This supports the assumption that firms learn about their competitors through common suppliers or consumers.

The work presented in this paper contributes to the empirical literature on incentives to form research joint ventures. The estimations are conducted on unusually large samples that enable to obtain robust results. Moreover, it is possible to distinguish between vertical and horizontal research joint ventures. After conducting a simple investigation into general firm characteristics that are associated with RJV participation, the analysis mainly focuses on horizontal research joint ventures, i.e. when firms engage in cooperative research with their direct competitors. The main objective of the paper is to find evidence for cost sharing in horizontal research joint ventures, as the theoretical literature argues that cost sharing is important mostly in this type of alliances. The econometric analysis is carried out in an endogenous switching model framework to confirm the existence of the cost sharing motive. ${ }^{3}$ I find evidence for cost sharing.

\footnotetext{
${ }^{3}$ According to my knowledge the only other paper using this type of modeling to deal with the above problem is that of Rõller, Tombak and Siebert (2000).
} 
Furthermore, I investigate the effect of debt levels on horizontal RJV participation. In a Chapter 2 I find that firms with a more leveraged capital structure are less reluctant to disclose their know-how to competitors and therefore competitors are more willing to engage in cooperative $R \& D$ with them. The empirical analysis finds evidence for the existence of this effect.

Finally, I test the effect of the change in the European legislation in 1993 that was supposed to encourage small firms to participate in RJVs. The evidence suggests that the policy has not reached its goal.

The structure of the paper is the following. I start with introducing the problems I study and the econometric framework. This section is followed by the discussion of the results and the final conclusion.

\subsection{Empirical investigation}

\subsubsection{Incentives to form research joint ventures}

In this section, I investigate the incentives to form research joint ventures. I mainly focus on three characteristics that influence the decision of participating in cooperative research consortia. The first characteristic is the firm size. I use three different variables to measure firm size, namely net real sales, real total assets and total employment. I expect that larger firms are more willing to conduct joint research. This would be consistent with the results of Tyler and Steensma (1995) and Cassiman and Veugelers (1998). As the database does not necessarily include all participants of an alliance I cannot analyze pairwise relationships between research partners as Roller et al (2000) do. They find that firms of the same size are likely to cooperate in R\&D.

The second characteristic is the $R \& D$ expenditure (or R\&D stock) of a given firm. We expect that firms with higher research spending are more willing to participate in cooperative research. The underlying explanation is twofold: more R\&D intensive firms may have more than one research projects running at a time and thus it is more likely that one of these projects is conducted jointly with another firm or research institution. Furthermore, firms with more experience in $\mathrm{R} \& \mathrm{D}$ can benefit more of joint research than the less experienced companies as their absorptive capacity is greater. Finally, an experienced firm is also a more appealing partner.

The third characteristic that is analyzed as a possible driver of RJV participation is former involvement in cooperative research. Firms with former experience in cooperative research might be able to exploit joint research better than other firms and therefore are more willing to form a 
new alliance. This hypothesis is very rarely tested as it requires panel data in order to construct the lag of RJV participation. ${ }^{4}$

I estimate a simple probit model with the above variables (and year and industry dummies) to analyze the incentives to form RJV's. The probit model is the estimation of a regression relationship:

$$
y_{i}^{*}=\beta^{\prime} x_{i}+u_{i},
$$

where $y_{i}^{*}$ is unobservable. Instead, we observe a dummy variable $y$ defined by:

$$
\begin{aligned}
& y_{i}=1 \quad \text { if } y_{i}^{*}>0, \\
& y_{i}=0 \quad \text { otherwise. }
\end{aligned}
$$

From the relationships in (4.1) and (4.2) we can derive the following:

$$
\begin{aligned}
\operatorname{Prob}\left(y_{i}=1\right) & =\operatorname{Prob}\left(u_{i}>-\beta^{\prime} x_{i}\right)= \\
& =1-F\left(-\beta^{\prime} x_{i}\right),
\end{aligned}
$$

where $F$ is the cumulative distribution for $u$. In the probit model we assume that $u_{i}$ follow the normal distribution $N\left(0, \sigma^{2}\right)$.

Note that the dependent variable in the estimated equations is either 0 or 1 . Therefore, whenever a firm has at least one RJV participation in a given year, $y_{i}$ is set to 1 . The equation I estimate is the following:

$$
P\left(R J V_{i t}=1\right)=\alpha S I Z E_{i t}+\beta r \& d s t o c k_{i t}+\gamma P P A R T_{i t}+u_{i t},
$$

where $S I Z E$ is approximated either with the logarithm of sales, assets or employment in turn, $r \& d s t o c k$ stands for the firm's log R\&D stock, and PPART is previous RJV participation. Year dummies and industry dummies based on 1-digit SIC codes are also included.

\subsubsection{Cost sharing in horizontal research joint ventures}

In this section I further analyze the cost sharing motive in horizontal research joint ventures. The theoretical literature states that cost sharing is an important incentive to form research joint ventures when the partners have homogeneous capabilities, i.e. when they are engaged in similar activities.

\footnotetext{
${ }^{4}$ Note that I am only able to account for RJV participation after 1985.
} 
To test the cost sharing hypothesis I would have to estimate the following probit regression for participation in horizontal research joint ventures: ${ }^{5}$

$$
P\left(H R J V_{i t}=1\right)=\beta X_{i t}+\gamma R \& D s a v_{i t}+u_{i t},
$$

where $X_{i t}$ stands for the firm characteristic variables and $R \& D s a v_{i t}$ denotes the $\mathrm{R} \& \mathrm{D}$ cost savings as result of (horizontal) cooperative research.

However, there are two problems that bias the estimation results of the above regression. Firstly, for a given year, a firm either participates in cooperative research or not. Therefore, its $\mathrm{R} \& \mathrm{D}$ expenditure is only observable for one of the cases (participation or non-participation). Secondly, there may be simultaneity between the decision to form a RJV and the R\&D expenditure. The cost saving may encourage firms to participate in $\mathrm{R} \& \mathrm{D}$ consortia and participation might reduce costs at the same time.

I estimate the following Lee endogenous switching model to overcome the above difficulties ${ }^{6}$ :

$$
\begin{aligned}
D R \& D I N T_{i t}^{H R J V_{i t}=1} & =\delta_{1} X_{1 i t}+u_{1 i t} \quad \text { if } \quad H R J V_{i t}=1 \\
D R \& D I N T_{i t}^{H R J V_{i t}=0} & =\delta_{2} X_{2 i t}+u_{2 i t} \quad \text { if } \quad H R J V_{i t}=0 \\
P\left(H R J V_{i t}=1\right) & =\delta_{3} X_{3 i t}+\gamma R \& D s a v_{i t}+u_{3 i t},
\end{aligned}
$$

where the vector of $\mathrm{Xs}$ are firm level variables, time and industry dummies, and:

$$
D R \& D I N T_{i t}=\left(R \& D_{i, t-1} / S A L E_{i, t-1}\right) /\left(R \& D_{i t} / S A L E i t\right)
$$

measures the decrease in the firm's R\&D intensity. Therefore it measures the cost saving of the firm. If this variable is greater than 1 , the firm's $R \& D$ intensity is decreasing, and it increases otherwise. Consequently,

$$
R \& D s a v_{i t}=D R \& D I N T_{i t}^{H R J V_{i t}=1}-D R \& D I N T_{i t}^{H R J V_{i t}=0} .
$$

measures the difference in cost saving between the two above scenarios.

The first equation of the endogenous switching model is estimated for firms that participate in at least one horizontal research alliance and equation (4.7) is estimated for firms that do not participate in horizontal research cooperation. Equation (4.8) is a probit regression where the

\footnotetext{
${ }^{5}$ And for the sake of completeness I have to repeat the exercise also for vertical RJVs.

${ }^{6}$ Econometrically, this problem is very similar to the problem of the effect of union participation on wages described by Lee(1978).
} 
cost saving of RJV participation appears as a regressor. If the cost sharing hypothesis holds, the coefficient of this variable is positive and significant.

The OLS estimate of equations 4.6 and 4.7 would be inconsistent. That is why a two-stage procedure is called for. Assuming that $X_{1}, X_{2}$ and $X_{3}$ are exogenous the model can be estimated starting with the estimation of the reduced form of the third equation:

$$
P\left(H R J V_{i t}=1\right)=\beta X_{i t}+\eta_{i t},
$$

where the matrix $X$ consists of all the variables in $X_{1}, X_{2}$ and $X_{3}$. The standard probit estimation of this equation is consistent.

Using the predicted probabilities $\hat{P}_{i t}$ after the estimation of (4.11), the R\&D savings equations can be estimated consistently by OLS after adding a selectivity correction term (Mills ratio):

$$
\begin{aligned}
& D R \& D I N T_{i t}^{H R J V_{i t}=1}=\delta_{1} X_{1 i t}+\sigma_{1 \eta} \frac{\phi\left(\hat{P_{i t}}\right)}{\Phi\left(\hat{P}_{i t}\right)}+\epsilon_{1 i t} \quad \text { if } \quad H R J V_{i t}=1 \\
& D R \& D I N T_{i t}^{H R J V_{i t}=0}=\delta_{2} X_{2 i t}+\sigma_{2 \eta} \frac{\phi\left(\hat{P}_{i t}\right)}{1-\Phi\left(\hat{P}_{i t}\right)}+\epsilon_{2 i t} \quad \text { if } \quad H R J V_{i t}=0,
\end{aligned}
$$

where $\phi()$ is the density function and $\Phi()$ is the distribution function of the standard normal distribution, $\sigma_{1 \eta}=-\operatorname{Cov}\left(u_{1}, \eta\right)$ and $\sigma_{2 \eta}=\operatorname{Cov}\left(u_{2}, \eta\right)$.

After obtaining the consistent estimates of equations (4.12) and (4.13), the predicted decrease in R\&D intensities, $D R \& \hat{D} I N T_{i t}{ }^{H R J V_{i t}=1}$ and $D R \& \hat{D} I N T_{i t}{ }^{H R J V_{i t}=0}$ can be calculated for the whole sample. Then, $R \& \hat{D} s a v_{i t}=D R \& \hat{D} I N T_{i t}{ }^{H R J V_{i t}=1}-D R \& \hat{D} I N T_{i t}{ }^{H R J V} V_{i t}=0$ can be used for estimating the parameters of the probit equation in $4.8 .^{7}$

If the cost sharing hypothesis is correct, then the coefficient of $R \& \hat{D} s a v_{i t}$ in the final probit estimation is positive and significant. Moreover, the coefficients of the Mills ratios in equations 4.12 and 4.13 prove whether there is indeed a selection bias. Maddala (1993) warns that the significance of the correction terms is often mistaken for a proof of the selection bias. It is rather the signs and magnitude of these coefficients that matter. Moreover, in the specification presented above $\sigma_{1 \eta}+\sigma_{2 \eta}>0$ should hold to justify the use of the method. ${ }^{8}$

\footnotetext{
${ }^{7}$ Alternatively, one could estimate the model like Rõller, Tombak and Siebert (2000). They investigate the incentives of two specific firms to cooperate. However, as my sample does not necessarily include both (or all) participants of an RJV, this method would substantially decrease the sample for which the estimation can be performed. Moreover, with the new interpretation we would have a double selection problem: firms choose to form RJVs and then choose a specific partner to form a research alliance.

${ }^{8}$ Further explanation will be provided when describing the results.
} 
The exact specification of the endogenous switching model estimated in this paper is:

$$
\begin{aligned}
& D \& D I N T_{i t}^{H R J V} V_{i t}=1=\delta_{1} r \& d s t o c k_{i, t-1}+\pi_{1} \text { assets }_{i t}+u_{1 i t} \text { if HRJV } V_{i t}=1 \\
& D R \& D I N T_{i t}^{H R J V_{i t}=0}=\delta_{2} r \& d s t o c k_{i, t-1}+\pi_{2} \text { assets }_{i t}+u_{2 i t} \text { if HRJV } V_{i t}=0 \\
& P\left(H R J V_{i t}=1\right)=\alpha_{3} P P A R T_{i, y-1}+\beta_{3} r \& d_{s t o c k}+\gamma_{3} \text { assets }_{i t}+ \\
& \eta_{3} R \& D s a v_{i t}+u_{3 i t} .
\end{aligned}
$$

\subsubsection{Limited liability and incentives to form horizontal research joint ven- tures}

In Chapter 2 I analyzed the moral hazard problem that in cooperative research agreements the information sharing, one main input of the joint research activity cannot be contracted. In horizontal research joint ventures firms have incentives not to share their know-how with their partners as it might give them advantage in the output market competition. I found that there is a direct relationship between the debt of the firm and its incentives to disclose its know-how. If debt financing is possible, under some conditions about the profit function, firms finance at least partially with debt. As a result, the equilibrium level of disclosure is higher than without the possibility of debt financing. That is, debt acts as a commitment device to share knowledge.

An empirical test of this statement is to test whether firms with more debt are more willing to form horizontal research joint ventures (or other firms are more open to accept them as research partners). The test is simply carried out in a probit framework where the debt of the firm is one of the regressors.

The probit equation I estimate on the US R\&D sample is the following:

$$
P\left(R J V_{i t}=1\right)=\alpha r \& d s t o c k_{i t}+\beta P P A R T_{i t}+\gamma d e b t_{i t}+u_{i t},
$$

where debt is the natural logarithm of the firm's total debt over net sales.

If more debt gives additional incentives to form horizontal research consortia then the coefficient of $d e b t_{i t}$ is positive and significant.

\subsubsection{European legislation and horizontal research joint ventures}

In 1993, the European legislation concerning research joint ventures changed. From that year on, firms can market their innovation together if their joint market share is less than $10 \%$. 
Theoretically, this change should encourage small firms to form more research joint ventures with their competitors as the expected rewards are greater.

To test whether this additional incentive is present, one has to estimate a probit regression (in the form of equation 4.4) for European horizontal RJV formation where a policy dummy interacted with a size variable appears. The policy dummy is simply set to 1 for years after 1992 . The preferred size variable would be market share. However, this information is not available. Therefore, I will experiment with several proxies, such as employment, total assets and net sales.

\section{Data}

The data come from three different sources. The information about research consortia comes from the SDCA-SDC Worldwide Joint Ventures \& Alliances database. ${ }^{9}$ I merged the above database with two other databases, which include firm level accounting data in a panel structure. The databases used for the matching are Global Vantage and Compustat. ${ }^{10}$ The Global Vantage database contains accounting data for large firms worldwide. The Compustat database has information about (mainly listed) North-American companies.

The merged database contains around 20,000 firms in a panel structure between 1985-1995 worldwide. There are around 900 firms that participate in $R \& D$ alliances. In this paper I use a subsample of European, Japanese and US firms. The dataset used in this paper contains an unbalanced panel of around 6200 firms for the period 1985-1995. This database is biased towards large firms. ${ }^{11}$

The variables used in the estimations are the following:

Sales, net real sales.

Employment, the variable measures the full-time, part-time and seasonal employment.

Assets, I use real total assets in million USD.

$R \xi D$ expenditure, in the original sample this variable is missing in many observations, mainly in Europe where firms are not legally required to disclose R\&D expenditure. The R\&D stock of firms also appears in the regression. ${ }^{12} \mathrm{R} \& \mathrm{D}$ expenditure is measured in thousand USD.

Total debt, the sum of total long term debt plus debt in current liabilities, measured in million USD.

\footnotetext{
${ }^{9}$ Thanks to Bruno Cassimann and the TSER Project SOE1-CT97-1059 for providing the data.

${ }^{10}$ Thanks to the IFS for the data.

${ }^{11}$ For detailed descriptive statistics see Appendix B.

${ }^{12}$ See Appendix B for details on the construction method.
} 
$R J V$ participation, the variable contains the number of research joint ventures the firm has joined since 1985. Since there is no information about research consortia participation before 1985, the levels of this variable may contain serious measurement error. I distinguish among three types of research joint ventures. I define horizontal RJVs as joint research between firms in industries with the same 2-digit SIC code. Similarly, vertical RJVs consist of firms from different 2-digit SIC industries. Research consortia that have a university participant are treated as vertical RJVs.

These above hypotheses are tested on four different samples. All samples are pooled, the panel properties are only exploited in using the lag of research joint venture participation. The first sample is the entire US, Japan and Europe sample with around 38600 observations (6200 firms). The second sample is based on the first, only that firms that have at least one new RJV participation during the sample period are included. The first two samples do not allow to explore the relationship between $R \& D$ spending and incentives to form research joint ventures as the $\mathrm{R} \& \mathrm{D}$ variable is often missing.

The third sample contains US firms with available information on research expenditures. The last sample is then the subsample of the third: it only contains firms that participate in at least one new research alliance.

Tables 4.1 and 4.2 give the number of firms with at least one new RJV participation per year in the mixed and in the US R\&D sample. The abrupt fall in the number of RJV participations is due to the fact that the versions of the Compustat and Global Vantage databases I used were not complete for 1995 . 
Table 4.1: New RJV participation - mixed sample

\begin{tabular}{lccc}
\hline \hline & horizontal & vertical & both \\
\hline 1985 & 0 & 0 & 0 \\
1986 & 0 & 6 & 0 \\
1987 & 0 & 3 & 0 \\
1988 & 5 & 5 & 0 \\
1989 & 3 & 15 & 4 \\
1990 & 16 & 56 & 5 \\
1991 & 27 & 80 & 12 \\
1992 & 32 & 84 & 9 \\
1993 & 20 & 73 & 10 \\
1994 & 33 & 74 & 16 \\
1995 & 7 & 14 & 1 \\
total & 143 & 410 & 57 \\
\hline sample size (observations) & 44858 & & \\
\hline
\end{tabular}

Table 4.2: New RJV participation - US R\&D sample

\begin{tabular}{lccc}
\hline \hline & horizontal & vertical & both \\
\hline 1985 & 0 & 0 & 0 \\
1986 & 0 & 4 & 0 \\
1987 & 0 & 2 & 0 \\
1988 & 4 & 2 & 0 \\
1989 & 2 & 7 & 2 \\
1990 & 9 & 24 & 5 \\
1991 & 12 & 35 & 9 \\
1992 & 19 & 42 & 4 \\
1993 & 10 & 35 & 7 \\
1994 & 18 & 42 & 6 \\
1995 & 1 & 3 & 0 \\
total & 75 & 196 & 33 \\
\hline sample size (observations) & 12438 & & \\
\hline
\end{tabular}




\subsection{Results}

\subsubsection{Incentives to form research joint ventures}

Table 4.3 contains the main results for the probit model that analyzes incentives to form any kind of research joint venture. The table shows selected results for all four samples. ${ }^{1314}$ The table only shows results with the total assets approximating the firm size. Results with sales and employment are very similar both qualitatively and quantitatively. 1-digit industry dummies are also included. The results with 2-digit industry dummies were essentially identical.

The first column contains estimation results for the whole European, US and Japanese sample. Consequently, the R\&D stock is not included amongst the explanatory variables. The second column also refers to this sample, but is only restricted for firms that participate at least once in a RJV. Columns three and four show estimation results for the US R\&D sample (wide US sample). I present two different specifications: in the first case, previous RJV participation is not differentiated by the type of alliance while in the second case both previous horizontal and vertical research cooperation appear as regressors. Columns five and six contain results for the same specifications for the restricted US sample. Note that the results from the restricted samples (both the mixed and the US sample) are somewhat difficult to interpret as firms included in those samples form RJVs at some point during the sample period. However, it is still interesting to compare the results with the results on the unrestricted samples.

It is quite clear that greater firms are more likely to engage in cooperative research: the asset variable is positive and significant in all estimations. The $\mathrm{R} \& \mathrm{D}$ stock variable is also positive and significant on both US samples. Therefore, one can conclude that greater R\&D stock results in stronger incentives to form research joint ventures, i.e. the absorptive capacity hypothesis holds.

Similarly, previous experience in cooperative research encourages RJV participation. Interestingly, it is participation in vertical rather than horizontal research consortia that turns a firm into a more attractive partner. This is consistent with the theoretical literature in the sense that the reason to form horizontal RJVs is rather cost sharing, obtaining information on the other firm's output market strategy and (possibly) engage in other type of cooperation than actually learning.

\footnotetext{
${ }^{13}$ For each sample there were twelve probit equations estimated. The full set of results is available on request.

${ }^{14}$ Note that although I use the same samples in all the estimations presented in this paper, estimations are based on different number of observations. This is due to the fact that as industry dummies are included, sometimes a specific industry predicts sure success or failure (in terms of probability of RJV participation). Consequently, these observation are dropped.
} 
Table 4.3: Incentives to form research joint ventures - probit (1985-1995)

\begin{tabular}{|c|c|c|c|c|c|c|}
\hline Independent variables & $\mathrm{I}$ & II & III & IV & $\mathrm{V}$ & VI \\
\hline \multirow{2}{*}{ assets $_{i t}$} & .266 & .131 & .115 & .117 & .094 & .098 \\
\hline & $(22.12)$ & $(8.01)$ & $(4.46)$ & $(4.52)$ & $(3.28)$ & $(3.42)$ \\
\hline \multirow[t]{2}{*}{$r \& d s t o c k_{i t}$} & & & .168 & .167 & .041 & .045 \\
\hline & & & $(7.05)$ & $(7.02)$ & $(1.76)$ & $(1.73)$ \\
\hline \multirow[t]{2}{*}{$P P A R T_{i t}$} & .272 & .031 & .171 & & .019 & \\
\hline & $(12.93)$ & $(1.69)$ & $(5.87)$ & & $(0.80)$ & \\
\hline \multirow[t]{2}{*}{ PHPART $i t$} & & & & -.020 & & -.105 \\
\hline & & & & $(-.24)$ & & $(-1.36)$ \\
\hline \multirow[t]{2}{*}{$P V P A R T_{i t}$} & & & & 0.257 & & .060 \\
\hline & & & & $(5.79)$ & & $(1.73)$ \\
\hline Pseudo R2 & .28 & .18 & .32 & .32 & .19 & .19 \\
\hline Number of obs. & 38636 & 3066 & 10793 & 10793 & 1498 & 1498 \\
\hline
\end{tabular}

All estimations include jointly significant time dummies. In the first four columns, 1-digit industry dummies are also added (z-values are in parentheses).

Table 4.4: Incentives to form research joint ventures - dprobit (1985-1995)

\begin{tabular}{lcccccc}
\hline \hline Independent variables & I & II & III & IV & V & VI \\
\hline assets $_{i t}$ & .003 & .029 & .002 & .002 & .021 & .022 \\
& & & & & & \\
r\&dstock & & & .002 & .002 & .009 & .009 \\
& & & & & & \\
PPART & & & & & .004 & \\
& .003 & .007 & .002 & & .004 & \\
PHPART & & & & & & \\
& & & & -.003 & & -.024 \\
PVPART & & & & & & \\
& & & & .003 & & .013 \\
\hline Pseudo R2 & & & & & & \\
\hline Number of obs. & 38636 & 3066 & 10793 & 10793 & 1498 & 1498 \\
\hline
\end{tabular}


The coefficients of a probit equation are not easy to interpret. To get the predicted effects of changes in the independent variables on the probability of participating in research joint ventures I present the derivatives of the probabilities for each independent variable around the mean of the variables. Table 4.4 shows the slope coefficients of the estimation results in the previous table. Note that when interpreting these results, on has to keep in mind that the asset and $R \& D$ stock variables are logged and that assets are measured in million USD while R\&D in thousand USD. For example, then the interpretation of a 0.029 slope parameter for the asset variable is the following: if the total assets of a firm increase 2.72 times at the means of the explanatory variables, then the probability of participating in a RJV increases by 2.9 percentage point.

Table 4.5 shows results for the same specifications as Table 4.3 , but the dependent variable now is participation in horizontal research joint ventures. The results are very similar to those in Table 4.3 although the marginal effects presented in Table 4.6 are smaller than before.

Tables 4.7 and 4.8 show results for participation in vertical research joint ventures. The results again are very similar to those in Table 4.3 with smaller marginal effects around the means.

The results of this section suggest that: $i$, larger firms are more likely to cooperate in R\&D; $i$, higher R\&D stock results in more willingness to cooperate; and iii, previous RJV participation gives additional incentives to join new research consortia.

\subsubsection{Cost sharing in horizontal research joint ventures}

In this section, I analyze the results of the two stage estimation procedure of the endogenous switching model specified in equations (4.14)-(4.16). That is, I test whether one of the incentives to form horizontal research consortia is cost sharing. First I estimate a reduced form probit equation followed by the estimation of the R\&D-savings equation for both participating and non-participating firms. Then, using the results of the first step I estimate a structural probit equation.

Table 4.9 presents the coefficients of the reduced form probit estimation for the whole US R\&D sample.

This equation includes the explanatory variables of all three equations and does not reflect any structure based on the theory. Therefore, the results are not necessarily meaningful. In any case, the coefficients have the expected signs. 
Table 4.5: Incentives to form horizontal research joint ventures - probit (1985-1995)

\begin{tabular}{|c|c|c|c|c|c|c|}
\hline Independent variables & $\mathrm{I}$ & II & III & IV & V & VI \\
\hline \multirow[t]{2}{*}{ assets $_{i t}$} & .248 & .116 & .112 & .112 & .069 & .070 \\
\hline & $(13.24)$ & $(5.03)$ & $(3.01)$ & $(3.01)$ & $(1.17)$ & $(1.19)$ \\
\hline \multirow[t]{2}{*}{$r \& d s t o c k_{i t}$} & & & .145 & .145 & .076 & .076 \\
\hline & & & $(4.35)$ & $(4.35)$ & $(1.25)$ & $(1.26)$ \\
\hline \multirow[t]{2}{*}{$P P A R T_{i t}$} & .159 & .065 & .113 & & .056 & \\
\hline & $(7.81)$ & $(3.32)$ & $(3.99)$ & & $(2.16)$ & \\
\hline \multirow[t]{2}{*}{ PHPART $i t$} & & & & .055 & & -.003 \\
\hline & & & & $(.58)$ & & $(-.04)$ \\
\hline \multirow[t]{2}{*}{$P V P A R T_{i t}$} & & & & .141 & & .079 \\
\hline & & & & $(2.95)$ & & $(1.99)$ \\
\hline Pseudo R2 & .27 & .11 & .28 & .28 & .12 & .12 \\
\hline Number of obs. & 30813 & 2521 & 8305 & 8305 & 1173 & 1173 \\
\hline
\end{tabular}

All estimations include jointly significant time and 1-digit industry dummies (z-values are in parentheses).

Table 4.6: Incentives to form horizontal research joint ventures - dprobit (1985-1995)

\begin{tabular}{lcccccc}
\hline \hline Independent variables & I & II & III & IV & V & VI \\
\hline assets $_{i t}$ & .001 & .013 & .001 & .001 & .008 & .009 \\
& & & & & & \\
r\&dstock & & & .001 & .001 & .010 & .010 \\
& & & & & & \\
PPART & & & & & .007 & \\
& .001 & .007 & .001 & & .007 & \\
PHPART & & & & & & \\
& & & & .000 & & -.000 \\
PVPART & & & & & & \\
& & & & .001 & & .010 \\
\hline Pseudo R2 & & & & & & \\
\hline Number of obs. & 30813 & 2521 & 8305 & 8305 & 1173 & 1173 \\
\hline
\end{tabular}


Table 4.7: Incentives to form vertical research joint ventures - probit (1985-1995)

\begin{tabular}{|c|c|c|c|c|c|c|}
\hline Independent variables & $\mathrm{I}$ & II & III & IV & $\mathrm{V}$ & VI \\
\hline \multirow[t]{2}{*}{ assets $_{i t}$} & .260 & .122 & .098 & .101 & .057 & .063 \\
\hline & $(19.64)$ & $(6.98)$ & $(3.18)$ & $(3.28)$ & $(1.82)$ & $(1.98)$ \\
\hline \multirow[t]{2}{*}{$r \& d s t o c k_{i t}$} & & & .178 & .177 & .059 & .058 \\
\hline & & & $(6.05)$ & $(6.02)$ & $(2.13)$ & $(2.09)$ \\
\hline \multirow{2}{*}{$P P A R T_{i t}$} & .247 & .060 & .164 & & .051 & \\
\hline & $(12.07)$ & $(3.15)$ & $(5.60)$ & & $(2.03)$ & \\
\hline \multirow[t]{2}{*}{ PHPART $i t$} & & & & -.067 & & -.104 \\
\hline & & & & $(-.77)$ & & $(-1.29)$ \\
\hline \multirow[t]{2}{*}{$P V P A R T_{i t}$} & & & & 0.264 & & .105 \\
\hline & & & & $(5.83)$ & & $(2.75)$ \\
\hline Pseudo R2 & .28 & .16 & .32 & .32 & .16 & .17 \\
\hline Number of obs. & 38636 & 3066 & 10793 & 10793 & 1498 & 1498 \\
\hline
\end{tabular}

All estimations include jointly significant time dummies. In the first four columns, 1-digit industry dummies are also added (z-values are in parentheses).

Table 4.8: Incentives to form vertical research joint ventures - dprobit (1985-1995)

\begin{tabular}{lcccccc}
\hline \hline Independent variables & I & II & III & IV & V & VI \\
\hline assets $_{i t}$ & .002 & .022 & .001 & .001 & .010 & .011 \\
& & & & & & \\
r\&dstock & & & .001 & .001 & .010 & .010 \\
& & & & & & \\
PPART & & & & & .009 & \\
& .002 & .011 & .001 & & .009 & \\
PHPART & & & & & & \\
& & & & -.001 & & -.018 \\
PVPART & & & & & & \\
& & & & & & \\
& & & & .002 & & .019 \\
\hline Pseudo R2 & .28 & .16 & .32 & .32 & .16 & .17 \\
\hline Number of obs. & 38636 & 3066 & 10793 & 10793 & 1498 & 1498 \\
\hline
\end{tabular}


Table 4.9: Cost sharing in horizontal RJVs - reduced form probit (1985-1995)

\begin{tabular}{|c|c|}
\hline Independent variables & $\mathrm{I}$ \\
\hline \multirow{2}{*}{ assets $_{i t}$} & .025 \\
\hline & $(.51)$ \\
\hline \multirow[t]{2}{*}{$r \& d s t o c k_{i t}$} & 1.091 \\
\hline & $(4.00)$ \\
\hline \multirow[t]{2}{*}{$r \& d s t o c k_{i, t-1}$} & -.823 \\
\hline & $(-3.12)$ \\
\hline \multirow[t]{2}{*}{$P P A R T_{i t}$} & .099 \\
\hline & $(3.52)$ \\
\hline Pseudo R2 & .28 \\
\hline Number of obs. & 6557 \\
\hline
\end{tabular}

The estimation includes jointly significant time and 1-digit industry dummies (z-values are in parentheses).

Table 4.10 shows the results of the estimation of equations (4.14) and (4.15) with the additional correction terms. The first column is then estimated for firms that form new horizontal research joint ventures in a given year and the second contains results for the other group of firms.

The evidence suggests that larger firms tend to increase their $R \& D$ intensities over time and this effect is stronger in firms that do not form new horizontal research joint venture for a given year. Larger previous R\&D stock results (not surprisingly) in greater R\&D savings of similar magnitude in both samples.

The Mills ratio in the first equation is negative but not significant. In the second equation it is positive and highly significant. The insignificance of one of the ratios does not reject the hypothesis that there is a selectivity bias. It means that the decrease in $R \& D$ intensity as a result of horizontal RJV participation does not differ from the overall mean for the firms that actually participate in those RJVs. Without more information, this would suggest that there is no cost sharing. However, the positive and significant Mills ratio in the second equation tells us that firms that do not participate in horizontal RJVs can cut their R\&D intensities more effectively outside such a cooperation than the mean for all firms! Therefore, there is indeed evidence for the cost sharing hypothesis in horizontal research cooperation, but the underlying reason is not that cooperating firms are more efficient in a cooperative situation than the others 
Table 4.10: Cost sharing in horizontal RJVs (1985-1995)

\begin{tabular}{lcc}
\hline \hline Independent variables & $\mathrm{I}$ & $\mathrm{II}$ \\
\hline assets $_{i t}$ & -.038 & -.134 \\
& $(-1.95)$ & $(-6.28)$ \\
r\&dstock & .030 & .041 \\
& $(1.45)$ & $(1.83)$ \\
Mills $1_{i t}$ & -.198 & \\
& $(-.88)$ & \\
Mills $2_{i t}$ & & 2.152 \\
& & $(1.76)$ \\
\hline Number of obs. & 106 & 6451 \\
\hline Adj. R2 & .013 & .010 \\
\hline
\end{tabular}

The estimation in the second column includes jointly significant time and 1-digit industry dummies (tvalues are in parentheses).

but rather that these firms would be less efficient in cost cutting outside of such an agreement!

Table 4.11 presents the estimate of the structural probit equation in (4.16). It confirms the existence of cost sharing: the coefficient of the R\&D savings variable is positive and highly significant. The interpretation of the slope coefficient is the following: if $R \& D I n t_{t-1} / R \& D I n t_{t}$ is one percentage point greater for participation than for non-participation, then the probability of participation in horizontal research cooperation increases by 0.00839 .

The result also confirms that previous participation increases the probability of participation in horizontal consortia. Similarly, greater R\&D spending implies greater probability of cooperation. However, when the R\&D saving is added to the explanatory variable the sign of the coefficient of firm size (assets) becomes negative. The underlying reason is that firm size is inversely related to the decrease in $R \& D$ intensity.

The results of the estimation of the endogenous switching model thus confirm the theoretical results: one of the reasons to engage in cooperative research with a competitor is cost saving. This is consistent with the findings of Sakakibara (1997) and Rõller et al. (2000). ${ }^{15}$

Note that this result is not necessarily welfare-improving: decreased $R \& D$ spending might be a reaction for decreased competition in the output market as a consequence of RJV formation.

\footnotetext{
${ }^{15}$ The estimation was carried out for vertical joint ventures without significant evidence for cost-reduction.
} 
Table 4.11: Cost sharing in horizontal RJVs - structural probit and dprobit (1985-1995)

\begin{tabular}{lcc}
\hline \hline Independent variables & I & II \\
\hline R\&Dsav $i t$ & 73.565 & .839 \\
& $(3.12)$ & \\
assets $_{i t}$ & -7.096 & -.081 \\
& $(-3.11)$ & \\
r\&dstock & \\
& 1.091 & .012 \\
& $(4.00)$ & \\
PPART & \\
& .099 & .001 \\
& $(3.52)$ & \\
\hline Pseudo R2 & .28 & \\
\hline Number of obs. & 6557 & \\
\hline
\end{tabular}

The estimation includes jointly significant time and 1-digit industry dummies (z-values are in parentheses).

\subsubsection{Limited liability and incentives to form horizontal research joint ven- tures}

Table 4.12 presents the results of the probit model in equation 4.17 for the two US samples (wide and restricted to cooperating firms). That is, I test whether higher debt increases participation in horizontal research joint ventures. Table 4.13 presents the slope coefficients of the estimation.

The effect of the capital structure on cooperation in $R \& D$ with competitors is less visible on the wide sample (and the effect is only significant on the $10 \%$ level in one of the specifications). However, the magnitude of the effect is quite significant on the restricted sample. A 2.72 times increase in the debt to sales ratio around the means increases the probability of horizontal cooperation by 0.015 . Thus, the magnitude of the effect is quite substantial. ${ }^{16}$

Consequently, empirical evidence confirms the existence of the limited liability effect in horizontal research joint venture formation.

\footnotetext{
${ }^{16}$ As debt might change more rapidly than other firm characteristics the results on the restricted sample is significant because firms are more heterogeneous in this respect.
} 
Table 4.12: Horizontal research joint ventures and the limited liability effect - probit (1985-1995)

\begin{tabular}{|c|c|c|c|c|c|c|}
\hline Independent variables & I & II & III & IV & $\mathrm{V}$ & $\mathrm{VI}$ \\
\hline \multirow[t]{2}{*}{$r \& d s t o c k_{i t}$} & .208 & .226 & .208 & .088 & .099 & .089 \\
\hline & $(9.16)$ & $(10.09)$ & $(9.13)$ & $(3.45)$ & $(3.86)$ & $(3.44)$ \\
\hline \multirow[t]{2}{*}{$P P A R T_{i t}$} & .134 & & & .069 & & \\
\hline & $(4.63)$ & & & $(2.59)$ & & \\
\hline \multirow[t]{2}{*}{ PHPART $_{i t}$} & & .269 & .065 & & .132 & .028 \\
\hline & & $(3.72)$ & $(.68)$ & & $(1.76)$ & $(.32)$ \\
\hline \multirow[t]{2}{*}{$P V P A R T_{i t}$} & & & .168 & & & .086 \\
\hline & & & $(3.45)$ & & & $(2.13)$ \\
\hline \multirow[t]{2}{*}{$\operatorname{debt}_{i t}$} & 0.063 & .069 & .065 & .110 & .117 & .112 \\
\hline & $(1.52)$ & $(1.64)$ & $(1.56)$ & $(2.04)$ & $(2.13)$ & $(2.07)$ \\
\hline Pseudo R2 & .27 & .25 & .26 & .10 & .10 & .10 \\
\hline Number of obs. & 7931 & 7931 & 7931 & 1156 & 1156 & 1156 \\
\hline
\end{tabular}

All estimations include jointly significant time dummies (z-values are in parentheses).

Table 4.13: Horizontal research joint ventures and the limited liability effect - dprobit (19851995)

\begin{tabular}{lcccccc}
\hline \hline Independent variables & I & II & III & IV & V & VI \\
\hline r\&dstock $i t$ & .001 & .001 & .001 & .012 & .013 & .012 \\
PPART & & & & & & \\
& .001 & & & .009 & & \\
PHPART & & & & & & \\
& & .001 & .000 & & .017 & .004 \\
PVPART & & & & & & \\
& & & .001 & & & .011 \\
debt & & & & & & \\
& & & & & \\
Pseudo R2 & 0.000 & .000 & .000 & .015 & .016 & .015 \\
\hline Number of obs. & & & & & & \\
\hline
\end{tabular}




\subsubsection{European legislation and horizontal research joint ventures}

To test the effect of the policy change I interact the size variable with a policy dummy that is set to 1 for years after 1992. If the policy was effective, then after 1992 the size would not matter as much as before. Therefore, the coefficient of the policy $*$ size variable would be negative and significant.

Table 4.14 presents the corresponding results. I have used the natural logarithm of net sales, total assets and employment to approximate size. The dependent variable is the probability of horizontal RJV participation in Europe. The sample is the whole set of US, Japanese and European firms.

Table 4.14: Industrial policy and horizontal RJV formation in Europe - probit (1985-1995)

\begin{tabular}{lccc}
\hline \hline Independent variables & I & II & III \\
\hline sales $_{i t}$ & .274 & & \\
& $(7.46)$ & & \\
assets $_{i t}$ & & .273 & \\
& & $(7.56)$ & \\
emp $_{i t}$ & & & .284 \\
& & & $(7.61)$ \\
PPART & & \\
& .066 & .061 & .073 \\
POLICY $*$ sales $_{i t}$ & .263 & & \\
& $(1.71)$ & & \\
POLICY $*$ assets & & .219 & \\
& & $(1.60)$ & \\
POLICY $*$ emp $_{i t}$ & & & .174 \\
& & & $(1.44)$ \\
\hline Pseudo R2 & .27 & 28 & .28 \\
\hline Number of obs. & 21320 & 21320 & 21320 \\
\hline
\end{tabular}

All estimations include jointly significant time and 1-digit industry dummies (z-values are in parentheses).

The results suggest that there was no change in European RJV formation between small firms in the same industry. Therefore, the 1993 change in European legislation did not reach its goal.

This result might be explained with a general change in research joint venture formation. 
Therefore, it would be necessary to compare results with RJV formation in Japan or the US for the same period before reaching a final conclusion.

\subsection{Conclusion}

I have analyzed the incentives of firms to form research joint ventures. I have found that greater firms are more willing to form research consortia. Similarly, greater R\&D spending results in greater willingness to cooperate. The absorption capacity hypothesis was also confirmed: firms with previous experience in research joint ventures have greater incentives to form a new one than other corporations.

Furthermore, I have found that one of the reasons for firms to join horizontal research joint ventures is cost saving. This result confirms that industrial policy that encourages the formation of horizontal research consortia may indeed enhance social welfare as it may prevent costly duplication of efforts.

I have also presented evidence that the limited liability effect is likely to play a role in participation in horizontal RJVs. Firms with more debt relative to net sales are more willing to form RJVs (or their partners are more willing to engage in cooperative research with them).

Finally, I have not found evidence that the 1993 change in European legislation regulating RJVs had increased the willingness of smaller firms to participate in horizontal research joint ventures. In this respect, further research is needed to confirm the results. 


\section{Appendix A: Proofs}

Proof of Proposition 2.1: The denominator of the expression in (2.16) is negative, since it is the second order condition. In the numerator $d \tilde{v} / d D^{i}>0$ (from (2.7)). So, the sign of $d \gamma^{i} / d D^{i}$ is the same as the sign of $-\left[\alpha^{i} P_{\gamma^{i}}+B_{\gamma^{i}}^{i}\right] f(\tilde{v})$. But this is the marginal profit evaluated in the lowest state of nature about which the shareholders care. And, from the first order condition (2.14) the sum of the marginal profits evaluated in all relevant states is zero. Given that $B_{\gamma^{i}}^{i}$ is independent of $v$, if $P_{\gamma v}>0$, then in the "starting point" $\tilde{v}^{i}$ the marginal profit should be negative. Thus $-\left[\alpha^{i} P_{\gamma^{i}}+B_{\gamma^{i}}^{i}\right] f(\tilde{v})$ is positive. That is, higher debt implies higher disclosure for given level of know-how disclosure of the other firm. The other two cases can be proved the same way.

Proof of Proposition 2.2: The equilibrium disclosure of the firms satisfy the two first order conditions:

$$
\begin{aligned}
& \int_{\tilde{v}^{i}}^{\bar{v}}\left[\alpha^{i} \frac{\partial P\left(v, \gamma^{1 *}, \gamma^{2 *}\right)}{\partial \gamma^{i}}+\frac{\partial B^{i}\left(\gamma^{1 *}, \gamma^{2 *}\right)}{\partial \gamma^{i}}\right] f(v) d v=0, \\
& \int_{\tilde{v}^{j}}^{\bar{v}}\left[\alpha^{j} \frac{\partial P\left(v, \gamma^{1 *}, \gamma^{2 *}\right)}{\partial \gamma^{j}}+\frac{\partial B^{j}\left(\gamma^{1 *}, \gamma^{2 *}\right)}{\partial \gamma^{j}}\right] f(v) d v=0 .
\end{aligned}
$$

The solution of this system of equations is $\gamma^{i *}\left(D^{i}, D^{j}\right)$ and $\gamma^{j *}\left(D^{i}, D^{j}\right)$. I can find $d \gamma^{i *} / d D^{i}$ and $d \gamma^{j *} / d D^{i}$ using the Implicit Function Theorem:

$$
\begin{gathered}
\frac{d \gamma^{i *}}{d D^{i}}=-\frac{S V^{i} \gamma^{i} \gamma^{j} \frac{d \gamma^{j *}}{d D^{i}}+S V_{\gamma^{i} D^{i}}^{i}}{S V^{i} \gamma^{i} \gamma^{i}} \\
\frac{d \gamma^{j *}}{d D^{i}}=-\frac{S V^{j} \gamma^{i} \gamma^{j} \frac{d \gamma^{i *}}{d D^{i}}}{S V^{j}{ }^{j} \gamma^{j}}
\end{gathered}
$$

Solving this system of equations:

$$
\frac{d \gamma^{i *}}{d D^{i}}=-\frac{S V^{i}{ }_{\gamma^{i} D^{i}} S V^{j}{ }_{\gamma^{j} \gamma^{j}}}{S V^{i}{ }_{\gamma^{i} \gamma^{i}} S V^{j}{ }_{\gamma^{j} \gamma^{j}}-S V^{i}{ }_{\gamma^{i} \gamma^{j}} S V^{j}{ }_{\gamma^{i} \gamma^{j}}},
$$




$$
\frac{d \gamma^{j *}}{d D^{i}}=\frac{S V^{i}{ }_{\gamma^{i} D^{i}} S V^{j}{ }_{\gamma^{i} \gamma^{j}}}{S V_{\gamma^{i} \gamma^{i}}^{i} S V^{j}{ }_{\gamma^{j} \gamma^{j}}-S V^{i} \gamma^{i} \gamma^{j} S V^{j}{ }_{\gamma^{i} \gamma^{j}}} .
$$

Using Assumption 2.1 and 2.2, and the fact that the sign of $S V^{i}{ }_{\gamma^{i} D^{i}}$ is the same as the sign of $P_{\gamma v}$, the proof is completed.

Proof of Proposition 2.3: To see the sign of the derivative in (2.19), one has to remember that:

a) $\frac{d \gamma^{i *}}{d D^{i}}$ and $\frac{d \gamma^{j *}}{d D^{i}}$ have the same sign as $P_{\gamma v}$ by Proposition 2.2 ,

b) $\int_{\underline{v}}^{\bar{v}}\left[\alpha^{i} P_{\gamma^{i}}+B_{\gamma^{i}}^{i}\right] f(v) d v$ has the opposite sign than $P_{\gamma v}$ (see the proof of Proposition 2.1), and

c) $\int_{\underline{v}}^{\bar{v}}\left[\alpha^{i} P_{\gamma^{j}}+B_{\gamma^{j}}^{i}\right] f(v) d v$ is always positive.

Therefore the first term of (2.19) is negative whatever is the relationship between the marginal profit and the states of nature. The second term is positive if the marginal profit is an increasing function of the realization of $v$ and negative if $P_{\gamma v}<0$.

So, if $P_{\gamma v}<0,(2.19)$ is always negative. Thus, the optimal choice of the owners of firm $i$ is $D^{i}=0$. When $P_{\gamma v}>0$ the first term of (2.19) is equal to zero for $D^{i}=0$, since it is identical to the first order condition of the second stage. The second term is positive. Thus, the optimal choice of the owners is financing at least partially with debt for any debt level of the other firm. Thus, the equilibrium debt levels are positive.

Proof of Corollary 2.1: In all cases when firms use debt financing it means also higher equilibrium disclosure of knowledge. But it results in higher industry profits.

Proof of Proposition 2.4: Using the constraint (2.21) and the definitions above, the proof of parts i) and ii) is trivial. In part iii) if $\left(D^{1 *}, D^{2 *}\right) \in P S^{1}$ but $\left(D^{1 *}, D^{2 *}\right) \notin P S^{2}$, firm 2 sets its best response debt level for $\hat{D}^{1}$. At the same time, firm 1 setting a debt level different from $\hat{D}^{1}$ and closer to its best response for $\left.D^{2}\left(\hat{D}^{1}\right)\right)$ could not attract firm 2 since the participation sets of the firms are strictly convex. Setting a debt further from its best response would make lower profit then borrowing $\hat{D}^{1}$. So, it is a Nash equilibrium. For the other case the proof follows the same steps. 


\section{Appendix B: Descriptive statistics}

\section{Mixed Sample}

The sample contains information of 6215 firms in an unbalanced panel with the length peaking around 10 periods (1828 firms). There are 389 firms participating in at least one research joint venture. The maximum number of research joint ventures (formed after 1985) a firm joins in a year is 10 .

The following table shows the means of the variables for the (sub)samples used in the different columns of Table 3.1 .

Table 4.15: Descriptive statistics - means

\begin{tabular}{lcc}
\hline \hline Variable & col I & col II and III \\
\hline net sales (million USD) & 1944 & 1974 \\
employment & 10927 & 11194 \\
total assets (million USD) & 2201 & 2240 \\
$\Delta$ RJV & 0.020 & 0.021 \\
\hline Number of obs. & 44858 & 42764 \\
Number of firms & 6215 & 5517 \\
\hline
\end{tabular}


The following table shows the number of observations per year for the (sub)samples used in the different columns of Table 3.1 .

Table 4.16: Number of observations per year

\begin{tabular}{lcc}
\hline \hline Year & col I & col II and III \\
\hline 1985 & 2862 & 2679 \\
1986 & 3983 & 3749 \\
1987 & 4704 & 4405 \\
1988 & 5074 & 4900 \\
1989 & 5193 & 4974 \\
1990 & 5169 & 4958 \\
1991 & 5060 & 4893 \\
1992 & 4390 & 4178 \\
1993 & 3882 & 3694 \\
1994 & 3592 & 3418 \\
1995 & 949 & 916 \\
\hline Number of obs. & 44858 & 42764 \\
\hline
\end{tabular}


The following table shows the balance of panel for the (sub)samples used in the different columns of Table 3.1 .

Table 4.17: Balance of panel

\begin{tabular}{lcc}
\hline \hline Period & col I & col II and III \\
\hline 3 & 698 & \\
4 & 692 & 692 \\
5 & 676 & 676 \\
6 & 465 & 465 \\
7 & 637 & 637 \\
8 & 420 & 420 \\
9 & 531 & 531 \\
10 & 1828 & 1828 \\
11 & 268 & 268 \\
\hline Number of firms & 6215 & 5517 \\
\hline
\end{tabular}

The following table shows the composition of the (sub)samples used in the different columns of Table 3.1 by country.

Table 4.18: Firms by country

\begin{tabular}{lcc}
\hline \hline Country/region & col I & col II and III \\
\hline USA & 3156 & 2894 \\
Europe & 1870 & 1546 \\
Japan & 1189 & 1077 \\
\hline Number of firms & 6215 & 5517 \\
\hline
\end{tabular}




\section{The US sample}

The sample contains information about 3156 firms. There are 238 firms participating in at least one research joint venture. The maximum number of research joint ventures (formed after 1985) a firm joins in a year is 10.

The subsample where information about R\&D spending is available contains data about 1574 firms. There are 181 firms participating in at least one research joint venture. The maximum number of research joint ventures (formed after 1985) a firm joins in a year is 10 . There are 143 firms that join vertical research joint ventures, 76 firms that start horizontal research joint ventures and 16 firms that engage in joint research with universities.

The following table shows the means of the variables for the (sub)samples used in Tables 3.2, 3.3 3.4 and 3.5. The first column corresponds to the sample used in the estimation of the first column of Table 3.2, the second column corresponds to the sample used in the last two columns of Table 3.2 and in all columns of Table 3.5. The third column corresponds to the sample used in Tables 3.3 and 3.4.

Table 4.19: Descriptive statistics - means

\begin{tabular}{lccc}
\hline \hline Variable & I & II & III \\
\hline net sales (million USD) & 1510 & 1542 & 1948 \\
employment & 9994 & 10171 & 11666 \\
total assets (million USD) & 1684 & 1724 & 1933 \\
$\Delta$ RJV & 0.021 & 0.022 & 0.037 \\
$\Delta$ VRJV & & & 0.084 \\
$\Delta$ RRJV & & & 0.030 \\
$\Delta$ URJV & & & 0.001 \\
R\&D expenditure (million USD) & & & 58 \\
\hline Number of obs. & 25570 & 24784 & 12364 \\
Number of firms & 3156 & 2894 & 1574 \\
\hline
\end{tabular}


The following table shows the number of observations per year for the (sub)samples used in the different columns of Table 3.2, 3.3, 3.4 and 3.5. The first column corresponds to the sample used in estimation of the first column of Table 3.2, the second column corresponds to the sample used in the last two columns of Table 3.2 and in all columns of Table 3.5. The third column corresponds to the sample used in Tables 3.3 and 3.4.

Table 4.20: Number of observations per year

\begin{tabular}{lccc}
\hline \hline Year & I & II & III \\
\hline 1985 & 2264 & 2161 & 1072 \\
1986 & 2480 & 2358 & 1199 \\
1987 & 2656 & 2522 & 1289 \\
1988 & 2662 & 2625 & 1305 \\
1989 & 2607 & 2584 & 1260 \\
1990 & 2543 & 2524 & 1235 \\
1991 & 2558 & 2538 & 1238 \\
1992 & 2562 & 2464 & 1241 \\
1993 & 2487 & 2378 & 1212 \\
1994 & 2340 & 2238 & 1141 \\
1995 & 411 & 392 & 246 \\
\hline Number of obs. & 25570 & 24784 & 12438 \\
\hline
\end{tabular}


The following table shows the balance of panel for the (sub)samples used in the different columns of Table 3.2, 3.3, 3.4 and 3.5. The first column correspond to the sample used in estimation of the first column of Table 3.2, the second column corresponds to the sample used in the last two columns of Table 3.2 and in all columns of Table 3.5. The third column corresponds to the sample used in Tables 3.3 and 3.4.

Table 4.21: Balance of panel

\begin{tabular}{lccc}
\hline \hline Period & I & II & III \\
\hline 3 & 262 & & 141 \\
4 & 273 & 273 & 155 \\
5 & 202 & 202 & 117 \\
6 & 176 & 176 & 93 \\
7 & 155 & 155 & 98 \\
8 & 186 & 186 & 80 \\
9 & 224 & 224 & 114 \\
10 & 1421 & 1421 & 636 \\
11 & 257 & 257 & 140 \\
\hline Number of firms & 3156 & 2894 & 1574 \\
\hline
\end{tabular}




\section{Bibliography}

[1] Arellano, M. and S. Bond, 1998, Dynamic Panel Data Estimation Using DPD98 - A Guide for Users, Institute for Fiscal Studies, mimeo.

[2] Arellano, M. and S. Bond, 1991, Some Tests of Specification for Panel Data: Monte Carlo Evidence and an Application to Employment Equations, Review of Economic Studies 58, 277-297.

[3] Baumol, 1999, Dissemination of inventions and technology consortia, mimeo.

[4] Beath,J., J Poyago-Theotoky and D.Ulph, 1998, Organization design and information sharing in a research joint venture with spillovers, Bulletin of Economic Research 50, 47-59.

[5] Bhattacharya, S., J. Glazer and D. E. M. Sappington, 1992, Licensing and the sharing of knowledge in research joint ventures, Journal of Economic Theory 56, 43-69.

[6] Bhattacharya, S. and G. Chiesa, 1995, Proprietary information, financial intermediation and research incentives, Journal of Financial Intermediation 4, 328-357.

[7] Blundell,R. and S.R. Bond, 1999, GMM estimation with persistent panel data: an application to production functions, The Institute for Fiscal Studies Working Paper Series W99/4.

[8] Brander, J. A. and T. R. Lewis, 1986, Oligopoly and financial structure: The limited liability effect, The American Economic Review 76, 956-970.

[9] Branstetter, L. and M. Sakakibara, 1998, Japanese research consortia: a microeconometric analysis of industrial policy, The Journal of Industrial Economics XLVI, 207-233.

[10] Cassiman, B. and R.Veugelers, 1998, R\&D cooperation and spillovers: some empirical evidence, mimeo, October 1998, Barcelona. 
[11] Choi, J. P., 1993, Cooperative R\&D with product market competition, International Journal of Industrial Organization 11, 553-571.

[12] Choi, J. P., 1992, Cooperative R\&D with moral hazard, Economics Letters 39, 485-491.

[13] d'Aspremont, C. and A. Jacquemin, 1988, Cooperative and noncooperative R\&D in a duopoly with spillovers, American Economic Review 78, 1133-1137.

[14] De Bondt, R. and R. Veugelers, 1991, Strategic investment with spillovers, European Journal of Political Economy 7, 345-366.

[15] De Bondt, R., P. Slaets and B. Cassiman, 1992, The degree of spillovers and the number of rivals for maximum effective $R \& D$, International Journal of Industrial Organization 10, $35-54$.

[16] Gandal, N. and S. Scotchmer, 1993, Coordinating research through research joint ventures, Journal of Public Economics 51, 173-193.

[17] Geroski, P.A., 1992, Antitrust policy towards cooperative R\&D ventures, Oxford Review of Economic Policy 9, 58-71.

[18] Irwin,D. and P.Klenow, 1996, High tech R\&D subsidies: the effects of Sematech, Journal of International Economics 40, 323-344.

[19] Jensen, R. A. and D. Showalter, 1999, Strategic debt and patent races, mimeo.

[20] Kamien, M. I., E. Muller and I. Zang, 1992, Research joint ventures and R\&D cartels, American Economic Review 82, 1293-1306.

[21] Kamien, M. I. and N. L. Schwartz, 1882, Market structure and innovation (Cambridge University Press, Cambridge).

[22] Katsoulacos, Y. and D. Ulph, 1998, Endogenous spillovers and the performance of research joint ventures, Journal of Industrial Economics 46, 333-357.

[23] Katz, M., 1986, An analysis of cooperative research and development, The Rand Journal of Economics 17, 527-543.

[24] Kesteloot, K. and R. Veugelers, 1995, Stable R\&D cooperation with spillovers, Journal of Economics \& Management Strategy 4, 651-672. 
[25] Lichtenberg,F.R., 1996, The European Strategic Program for Research in Information Technologies (ESPRIT): An Ex-Post Analysis, Columbia PaineWebber Working Paper Series in Money, Economics and Finance 96/09, 30-68.

[26] Martin, S., 1994, Private and social incentives to form R\&D joint ventures, Review of Industrial Organization 9, 157-171.

[27] Myers, S. C. and N. S. Majluf, 1984, Corporate financing and investment decisions when firms have information about that investors do not have, Journal of Financial Economics $13,187-221$.

[28] Narayanan, M. P., 1988, Debt versus equity under asymmetric information, Journal of Financial and Quantitative Analysis 23, 39-51.

[29] Nickell,S., 1996, Competition and corporate performance, Journal of Political Economy 104, 724-746.

[30] Pérez-Castrillo, J. D. and J. Sandonís, 1996, Disclosure of know-how in research joint ventures, International Journal of Industrial Organization 15, 51-75.

[31] Poitevin, M., 1989, Financial signalling and the "deep-pocket" argument, The RAND Journal of Economics 20, 26-40.

[32] Ross, S. A., 1977, The determination of financial structure: the incentive signalling approach, The Bell Journal of Economics 8, 23-40.

[33] Rõller, L., M.Tombak and R.Siebert, 2000, Why firms form research joint ventures: theory and evidence, mimeo.

[34] Sakakibara M., 1997, Heterogeneity of firm capabilities and cooperative research and development: an empirical examination of motives, Strategic Management Journal 18, 143-164.

[35] Sakakibara M., 2001, The diversity of R\&D consortia and firm behavior: Evidence from Japanese data, The Journal of Industrial Economics XLIX, 181-196.

[36] Sandonís, J., 1993, Rupturas en proyectos conjuntos de investigación, Revista Española de Economia, Monografico: Investigación y Desarrollo, 165-190.

[37] Scott, J.T., 1996, Environmental research joint ventures among manufacturers, Review of Industrial Organization 11, 655-679.

[38] Showalter, D., 1995, Oligopoly and financial strcture: comment, American Economic Review 83, 647-653. 
[39] Showalter, D., 1999, Strategic debt: evidence in manufacturing, International Journal of Industrial Organization 17, 319-333.

[40] Siebert,R., 1997, The impact of research joint ventures on firm performance: an empirical assessment, WZB Working paper.

[41] Sleuwaegen,L., G.Hartog and H Commandeur, 1995, International strategic alliances of leading dutch firms: market responses following the type of alliance and nationality of the partner, Working Paper Erasmus University Rotterdam.

[42] Tyler, B.B. and H.K. Steensma, 1995, Evaluating technological collaborative opportunities: a cognitive modeling perspective, Strategic Management Journal 16, 43-70.

[43] Veugelers, R., 1998, Collaboration in R\&D: an assessment of theoretical and empirical findings, De Economist 146, 419-443.

[44] Veugelers, R. and K. Kesteloot, 1994, On the design of stable joint ventures, European Economic Review 38, 1799-1815. 